\title{
Structural variability of EspG chaperones from mycobacterial ESX-1, ESX-3 and ESX-5 type VII secretion systems
}

\author{
Anne T. Tuukkanen ${ }^{1}$, Diana Freire ${ }^{1}$, Sum Chan ${ }^{2}$, Mark A. Arbing ${ }^{2}$, Robert W. Reed ${ }^{3, \#,}$ \\ Timothy J. Evans ${ }^{3, \#}$, Grasilda Zenkeviciutè ${ }^{1, \&}$, Jennifer Kim² ${ }^{2}$, Sara Kahng ${ }^{2}$, Michael R. \\ Sawaya $^{2}$, Catherine T. Chaton ${ }^{3}$, Matthias Wilmanns ${ }^{1}$, David Eisenberg ${ }^{2}$, Annabel H. A. \\ Parret ${ }^{1,{ }^{*}}$, and Konstantin V. Korotkov ${ }^{3,{ }^{*}}$ \\ ${ }^{1}$ European Molecular Biology Laboratory, Hamburg Unit, Hamburg, 22607, Germany \\ ${ }^{2}$ UCLA-DOE Institute, University of California Los Angeles, Los Angeles, California, 90095, \\ United States of America \\ ${ }^{3}$ Department of Molecular \& Cellular Biochemistry, and Center for Structural Biology, University of \\ Kentucky, Lexington, Kentucky, 40536, United States of America
}

\section{Abstract}

Type VII secretion systems (ESX) are responsible for transport of multiple proteins in mycobacteria. How different ESX systems achieve specific secretion of cognate substrates remains elusive. In the ESX systems, the cytoplasmic chaperone EspG forms complexes with heterodimeric PE-PPE substrates that are secreted from the cells or remain associated with the cell surface. Here we report the crystal structure of the $\mathrm{EspG}_{1}$ chaperone from the ESX-1 system determined using a fusion strategy with $\mathrm{T} 4$ lysozyme. $\mathrm{EspG}_{1}$ adopts a quasi 2-fold symmetric structure that consists of a central $\beta$-sheet and two a-helical bundles. Additionally, we describe the structures of $\mathrm{EspG}_{3}$ chaperones from four different crystal forms. Alternate conformations of the putative PE-PPE binding site are revealed by comparison of the available $\mathrm{EspG}_{3}$ structures. Analysis of $\mathrm{EspG}_{1}, \mathrm{EspG}_{3}$ and $\mathrm{EspG}_{5}$ chaperones using small-angle X-ray scattering (SAXS) reveals that $\mathrm{EspG}_{1}$ and $\mathrm{EspG}_{3}$ chaperones form dimers in solution, which we observed in several

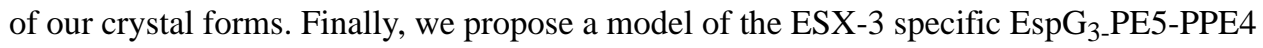
complex based on the SAXS analysis.

\footnotetext{
*Correspondence to: Annabel H. A. Parret (parret@embl-hamburg.de), Konstantin V. Korotkov (kkorotkov@uky.edu).

\#Present address: Division of Regulatory Services, College of Agriculture, Food and Environment, University of Kentucky, Lexington, Kentucky, 40536, United States of America

\&Present address: Department of Pharmacology, University of Cambridge, Cambridge, CB2 1PD, United Kingdom</address>

Publisher's Disclaimer: This is a PDF file of an unedited manuscript that has been accepted for publication. As a service to our customers we are providing this early version of the manuscript. The manuscript will undergo copyediting, typesetting, and review of the resulting proof before it is published in its final citable form. Please note that during the production process errors may be discovered which could affect the content, and all legal disclaimers that apply to the journal pertain.

Accession numbers

The structure factors and atomic coordinates have been deposited in the Protein Data Bank under accession codes 5VBA (T4LEspG $_{1 \mathrm{mka}}$ ), 5DLB (EspG3mma), 4L4W, 4RCL and 5SXL (EspG3msm). The SAXS data were deposited in the SASBDB under accession codes SASDDQ2, SASDDR2, SASDDS2, SASDDT2, SASDDU2, SASDDV2, SASDDW2, SASDDX2.
} 


\section{Keywords}

Mycobacterium tuberculosis; protein export; small-angle X-ray scattering; PE-PPE proteins

\section{Introduction}

The most deadly bacterial pathogen worldwide is Mycobacterium tuberculosis (Mtb), which causes tuberculosis (TB). While many infectious diseases can be controlled by vaccination, TB lacks an effective vaccine and even prior infection with $M t b$ does not provide lasting immunity. Moreover, standard anti-TB therapy requires the use of a combination of drugs for six months, which leads to poor compliance and to emergence of drug resistance [1]. Even more threatening is the global increase in extensively drug-resistant $M t b$ and the emergence of extremely drug-resistant $M t b$. Anti-virulence drugs targeting mycobacterial secretion have the potential to become a valuable alternative to classical antibiotics [2]. During infection, pathogenic mycobacteria use several related protein secretion pathways designated ESX systems [3-5]. The Mtb genome encodes five such secretion systems, ESX-1 through ESX- 5. Each consists of ATPases, membrane proteins, a protease, accessory proteins, and secreted substrates [6,7]. Four conserved components of the ESX-5 system $\mathrm{EccB}_{5}, \mathrm{EccC}_{5}, \mathrm{EccD}_{5}$ and $\mathrm{EccE}_{5}$ - form a platform complex with six-fold symmetry that is embedded in the mycobacterial inner membrane $[8,9]$. The ESX-1 core complex is composed of paralogous components [10], which suggests that all ESX systems assemble into similar complexes. Many ESX-secreted substrates are interdependent on each other for secretion, suggesting that they might be a part of the ESX secretion machinery [11, 12]. The most abundant class of ESX substrates is represented by the so-called PE and PPE proteins [13]. These proteins generally form alpha-helical heterodimers that are probably secreted in a folded conformation [14]. Several PE/PPE proteins are major antigens for TB diagnostic and vaccine development [15-19]. Importantly, PE/PPE proteins are secreted specifically by their cognate ESX secretion systems [20-24] raising the question of how various ESX systems discriminate among PE/PPE substrates.

Previously it was demonstrated that PE/PPE protein secretion in Mycobacterium marinum is impaired upon disruption of the $\operatorname{es} \mathrm{G}$ gene encoded within its respective ESX gene locus leading to accumulation of substrates in the bacterial cytosol [25]. The crystal structure of the heterotrimeric EspG 5 -PE25-PPE41 protein complex revealed that EspG ${ }_{5}$ interacts with a PE25-PPE41 heterodimer by binding to a hydrophobic patch at the tip of PPE41 [26, 27].

The general YxxD/E secretion motif $[28,29]$ at the distal end of PE25 is free to interact with the ESX-5 secretion machinery in the inner membrane, probably by interaction with the Ftsk/SpoIIIE-like ATPase $\mathrm{EccC}_{5}$ [30, 31]. In addition, $\mathrm{EspG}_{5}$ was reported to improve solubility of aggregation-prone PE-PPE pairs upon co-expression [26, 32]. Thus, EspG acts as a disaggregase of ESX substrates in the cytosol prior to secretion. Moreover, substrate specificity is determined by the EspG-binding domain of PPE proteins as demonstrated by substrate re-routing experiments [33]. While structures of the $\mathrm{EspG}_{5}$ chaperone in complexes with PE-PPE substrates and a monomeric EspG 3 chaperone have been reported $[26,27,34]$, structural information on $\mathrm{EspG}_{1}$ is lacking. 
In this study, we report the first crystal structure of an $\mathrm{EspG}_{1}$ chaperone from Mycobacterium kansasii and four crystal structures of $\mathrm{EspG}_{3}$ from M. smegmatis and $M$. marinum. We analyze here the available atomic structures of EspG chaperones and present a thorough study of the conformational variability of EspG proteins in apo and substratebound forms (EspG-PE-PPE) using small-angle X-ray scattering (SAXS). In addition, we characterize the SAXS-based rigid-body structure of the EspG 3 -PE5-PPE4 protein complex in solution and compare it to the atomic structure of EspG5-PE25-PPE41 in order to obtain further insights into protein flexibility and substrate recognition. Our study shows that the EspG chaperones are capable of adopting multiple conformational states, likely a key determinant of their ability to recognize multiple PE-PPE substrates.

\section{Results}

\section{The crystal structure of $M$. kansasii EspG $_{1}$}

Initial attempts to crystallize M. tuberculosis $\mathrm{EspG}_{1}\left(\mathrm{EspG}_{1 \mathrm{mtu}}\right)$ were not successful; therefore we screened several homologs of $\mathrm{EspG}_{1}$ from other mycobacterial species. We obtained microcrystals using an optimized construct of $M$. kansassi $\operatorname{EspG}_{1}\left(\mathrm{EspG}_{1 \mathrm{mka}}\right)$ that has $80 \%$ sequence identity with $\mathrm{EspG}_{1 \mathrm{mtu}}$ (Supplementary Fig. S1). However, extensive optimization of these crystals did not lead to diffraction quality crystals. To overcome these difficulties, we utilized a fusion approach using maltose binding protein or T4 lysozyme (T4L) as the $\mathrm{N}$ - terminal fusions. Whereas maltose binding protein fusion did not crystallize, crystals of the T4L-EspG $\mathrm{F}_{1 \mathrm{mka}}$ fusion could be readily optimized and diffracted to $2.27 \AA$ resolution. The structure of $\mathrm{T} 4 \mathrm{~L}-\mathrm{EspG}_{1 \mathrm{mka}}$ was solved by molecular replacement and refined to $R_{\text {work }} 0.214$ and $R_{\text {free }} 0.251$ with good geometry (Table 1 ). The structure contains two molecules in the asymmetric unit (Fig. 1a) with an extensive interface between the T4L moieties (2250 $\AA^{2}$ buried surface area). Surprisingly, part of the TEV cleavage sequence at the $\mathrm{N}$-terminus of $\mathrm{T} 4 \mathrm{~L}$ is ordered in the structure and contributes both to the $\mathrm{T} 4 \mathrm{~L}$ dimer interface ( $849 \AA^{2}$ buried surface area corresponding to $38 \%$ of the T4L-T4L interface) and the intra-subunit contacts between $\mathrm{T} 4 \mathrm{~L}$ and $\mathrm{EspG}_{1 \mathrm{mka}}$. The conformations of the two copies of $\mathrm{EspG}_{1 \mathrm{mka}}$ in the asymmetric unit are very similar and superimpose with a root-meansquare deviation (RMSD) of $1.0 \AA$ Aver $231 \mathrm{Ca}$ atoms (Supplementary Fig. S2). EspG $\mathrm{G}_{1 \mathrm{mka}}$ has a typical EspG fold characterized by a central anti-parallel $\beta$-sheet and two a-helical bundles (Fig. 1b). Several parts of the $\mathrm{EspG}_{1 \mathrm{mka}}$ structure did not have interpretable electron density and were not modeled, including the loop preceding the a 2 helix (chains $\mathrm{A}$ and $\mathrm{B}$ ), the $\beta 2-\beta 3$ loop (chain A), part of the $\beta 6$ strand (chain B), and the $\alpha 6$ helix (chains A and B) (Fig. 1a). The residues corresponding to the $\mathrm{C}$-terminal helical bundle displayed higher $B$ factors compared to other parts of the structure (Supplementary Fig. S2b). The C-terminal helical bundle likely forms part of the substrate recognition site and could become more ordered upon binding of a cognate PE-PPE dimer. The N-terminal and C-terminal subdomains of $\mathrm{EspG}_{1 \mathrm{mka}}$ are related by a quasi two-fold symmetry, have $10 \%$ sequence identity, and can be superimposed with a RMSD of $2.7 \AA$ over $71 \mathrm{Ca}$ atoms (Supplementary Fig. S3). 


\section{The EspG fold is conserved in ESX-1, ESX-3 and ESX-5 systems}

In order to extend the structural knowledge of the EspG-substrate interaction and the differences between these interactions in ESX-1, ESX-3 and ESX-5 secretion, we determined additional crystal structures of the EspG chaperones from the ESX-1 and ESX-3 systems (Table 1). Despite the fact that EspG chaperones display the lowest level of protein sequence similarity (13-23\% sequence identity) of all the core components of the ESX systems, the EspG 1, EspG $_{3}$ and EspG ${ }_{5}$ structures have a highly similar fold (Fig. 2, Fig. 3, Supplementary Figs. S4 and S5 and Supplementary Table S1). RMSD of the aligned atoms for EspG superposition is $2.4 \AA$ for $\mathrm{EspG}_{1 \mathrm{mka}}$ vs. $\mathrm{EspG}_{5 \mathrm{mtu}}$ over $224 \mathrm{Ca}$ atoms, $2.4 \AA$ for $\mathrm{EspG}_{3 \mathrm{mma}}$ vs. EspG $\mathrm{G}_{5 \mathrm{mtu}}$ over $238 \mathrm{Ca}$ atoms and $2.4 \AA$ for $\mathrm{EspG}_{1 \mathrm{mka}}$ vs. $\mathrm{EspG}_{3 \mathrm{mma}}$ over 234 $\mathrm{Ca}$ atoms. Despite the high overall structural similarity, the C-terminal helical bundles of $\mathrm{EspG}_{1 \mathrm{mka}}$ and $\mathrm{EspG}_{3}$ structures have a distinct conformation, when compared to the EspG $_{5 \mathrm{mtu}}$ structure bound to the PE25-PPE41 dimer, which appears to be incompatible with substrate binding (Fig. 3). Another significant difference is the length and the conformation

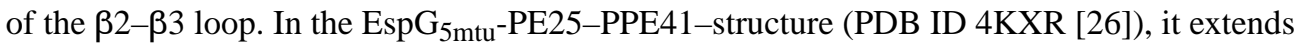
23 amino acid residues (Gly ${ }^{92}-\mathrm{Asn}^{114}$ ) and interacts strongly with the PE25-PPE41 dimer, whereas, for example, in the $\mathrm{EspG}_{3 \mathrm{msm}}$ (PDB ID 4L4W) structure the loop consists of only 12 amino acid residues ( $\mathrm{Ser}^{87}$ Leu $^{98}$ ). These structural differences could be explained by conformational changes in $\mathrm{EspG}_{5 \mathrm{mtu}}$ induced by PE-PPE binding, suggesting that binding of $\mathrm{EspG}_{1}$ and $\mathrm{EspG}_{3}$ to their cognate PPE protein partners is different from the $\mathrm{EspG}_{5}$ PPE41 interaction observed in the EspG ${ }_{5 \mathrm{mtu}}-\mathrm{PE} 25-\mathrm{PPE} 41-$ structure.

\section{Variation of quaternary structure within the EspG protein family}

Analysis of crystal packing in the available $\mathrm{EspG}_{3}$ structures revealed a number of possible quaternary arrangements in addition to the monomeric state. Firstly, a "wing-shaped dimer" was found in the asymmetric unit of the $\mathrm{EspG}_{3 \mathrm{msm}}$ (PDB ID 4L4W) structure with $1892 \AA^{2}$ buried surface area (Fig. 4). The dimeric interface is mediated by residues from the Cterminal helical bundles and strands $\beta 6, \beta 10, \beta 11$ and helix $a 8$. In contrast, the asymmetric unit of the $\mathrm{EspG}_{3 \mathrm{msm}}$ (PDB ID 4RCL) structure contains a dimer in front-to-front orientation with $1761 \AA^{2}$ buried surface area. The $\beta 8$ strands from the two subunits are located at the core of the interface and form an inter-subunit $\beta$-sheet. This dimeric conformation is further referred to as a " $\beta 8$-mediated dimer". However, in addition a "wingshaped dimer" similar to the $\mathrm{EspG}_{3 \mathrm{msm}}$ (PDB ID 4L4W) structure is present in the crystal lattice, with $2054 \AA^{2}$ buried surface area. Furthermore, the asymmetric unit of the $\mathrm{EspG}_{3 \mathrm{msm}}$ (PDB ID 4W4J [27]) structure also contains a similar wing-shaped dimer with substantial buried surface area as well as an $\beta 8$-mediated dimer (Fig. 4).

Altogether, $\mathrm{EspG}_{3 \mathrm{msm}}$ wing-shaped dimers are observed in three independent crystal structures, and $\beta 8$-mediated dimers are seen in two crystal structures. The dimer interfaces are highly similar, with the subunits rotated relative to each other by 12 degrees in the wingshaped dimers and 5 degrees in the $\beta 8$-mediated dimers (Supplementary Fig. S6). The different quaternary structures of EspG chaperones reflect the variability that exists within this protein family (Table 2). As previously proposed [26], EspG likely acts as a chaperone that maintains PE/PPE secretion targets in the cytosol in a soluble state. Further experiments will be required to elucidate whether the dimerization of $\mathrm{EspG}_{3 \mathrm{msm}}$ plays a role in the 
function of the chaperone in vivo. To assess whether EspG proteins of ESX-1 and ESX-5 display similar oligomerization behavior in solution, we performed a structural analysis of several EspG proteins in solution.

\section{Concentration-dependent oligomerization of EspG chaperones}

We studied solution structures of EspG proteins from ESX-1 (EspG $\left.{ }_{1 \mathrm{mma}}\right)$, ESX-3 $\left(\mathrm{EspG}_{3 \mathrm{mma}}, \mathrm{EspG}_{3 \mathrm{mtu}}, \mathrm{EspG}_{3 \mathrm{msm}}\right)$ and ESX-5 (EspG $\left.{ }_{5 \mathrm{mtu}}\right)$ secretion systems using SAXS (Table 3). The EspG proteins from different secretion systems have diverged significantly although the $\mathrm{EspG}_{3}$ homologs from different species have a high degree of sequence identity. The Guinier analysis of the obtained SAXS profiles confirmed that the proteins were not aggregated allowing further analysis of their structures and oligomeric states (Table 3). The dependencies of the molecular weight estimates and the excluded volume of the hydrated particles on concentration were studied for all proteins. Prior structural information of the monomeric form existed for all of the studied proteins, but experimental models of the dimeric state were only available for $\mathrm{EspG}_{3 \mathrm{msm}}$.

SAXS measurements of $\mathrm{EspG}_{1 \mathrm{mma}}$ at four different protein concentrations resulted in distinct scattering profiles. The molecular weight (based on the Porod volume) increased with increasing concentration from 43 to $72 \mathrm{kDa}$ at $1.0 \mathrm{mg} / \mathrm{mL}$ and $6.0 \mathrm{mg} / \mathrm{mL}$, respectively (Table 3). A similar trend was observed for the $R_{g}$ and $D_{\max }$ values. The oligomer analysis of the concentration-dependent SAXS data was carried out using theoretical scattering profiles based on the monomeric $\mathrm{EspG}_{1 \mathrm{mka}}$ (PDB ID 5VBA) structure and two different dimeric structural models. The $\beta 8$-mediated dimer observed in the $\mathrm{EspG}_{3 \mathrm{msm}}$ (PDB ID 4RCL) structure and the wing-shaped dimer structure of $\mathrm{EspG}_{3 \mathrm{msm}}$ (PDB ID 4L4W) were used as templates to generate $\mathrm{EspG}_{1 \mathrm{mma}}$ dimer models. The corresponding theoretical scattering profiles were exploited to decompose the experimental data (Table 4). The OLIGOMER analysis showed that $\mathrm{EspG}_{1 \mathrm{mma}}$ is predominantly a monomer at low protein concentrations, while the fraction of dimeric protein increases up to $50 \%$ at the highest concentration measured. However, the goodness-of-fit $\left(\chi^{2}\right)$ of the theoretical scattering based on linear combinations of theoretical monomer/dimer scattering profiles to the experimental SAXS data varied significantly between the two dimer models (Table 4). The SAXS data could not be interpreted successfully using the $\beta 8$-mediated dimeric arrangement (Table 4). Additional evidence that the $\beta 8$-mediated dimer is a non-physiological crystallographic dimer is the substantial structural clashes observed when the $\beta 8$-mediated $\mathrm{EspG}_{1}$ dimer is superimposed onto the $\mathrm{EspG}_{5 \mathrm{mtu}}$ structure derived from the heterotrimeric EspG $_{5 \mathrm{mtu}}-\mathrm{PE} 25-\mathrm{PPE} 41$ crystal structure (Fig. 3). The wing-shaped dimer conformation based on the $\mathrm{EspG}_{3 \mathrm{msm}}$ (PDB ID 4L4W) crystal structure yields better fits $\left(\chi^{2}\right.$-values between 0.79 and 1.27 , Table 4 ) to the measured scattering data, which strongly indicates that $\mathrm{EspG}_{1}$ dimers adopt the wing- shaped conformation in solution.

The program OLIGOMER was also used to fit a set of theoretical scattering profiles of monomeric and dimeric $\mathrm{EspG}_{3}$ models to the experimental $\mathrm{EspG}_{3 \mathrm{mtu}} \mathrm{SAXS}$ data. A dimer model was constructed based on the wing-shaped dimer structure of $\mathrm{EspG}_{3 \mathrm{msm}}$ (PDB ID $4 \mathrm{~L} 4 \mathrm{~W})$. All fits at different concentrations provided good $\chi^{2}$ values indicating that our wing- shaped dimer $\mathrm{EspG}_{3 \mathrm{mtu}}$ model based on the $\mathrm{EspG}_{3 \mathrm{msm}}$ structure is appropriate. 
Analysis of the volume distributions of the oligomeric states showed that even at the lowest concentration $(1.1 \mathrm{mg} / \mathrm{mL}), 46 \%$ of the protein was in dimeric form. The dimeric protein fraction increased to $100 \%$ at the highest measured concentration $(6.1 \mathrm{mg} / \mathrm{mL})$ (Table 4$)$. Likewise, the volume fractions of the oligomeric states were calculated for $\mathrm{EspG}_{3 \mathrm{mma}}$. Again the dimeric experimental structure of $\mathrm{EspG}_{3 \mathrm{msm}}$ (PDB ID 4L4W) was used as the template to model the dimeric form of $\mathrm{EspG}_{3 \mathrm{mma}}$. $\mathrm{EspG}_{3 \mathrm{mma}}$ showed a similar oligomerization pattern as $\mathrm{EspG}_{3 \mathrm{mtu}}$. The volume fraction of the dimeric form of the protein is above $46 \%$ even at the lowest protein concentration (Table 4).

We measured the SAXS profiles of two different $\mathrm{EspG}_{3 \mathrm{msm}}$ protein preparations, native and selenomethionine (SeMet) incorporated forms. Interestingly, the two proteins showed distinct oligomerization behaviors. The native $\mathrm{EspG}_{3 \mathrm{msm}}$ sample had a significant fraction of the dimeric form present already at the lowest measured concentration and the fraction stayed stable as the protein concentration increased (Table 4). On the contrary, the SeMetlabeled form remained monomeric over the whole concentration range (Table 4). The CRYSOL fit of the monomeric structure (PDB ID 4L4W) to the scattering data from the SeMet-labeled construct provided a $\chi^{2}$ value of 0.93 . This enabled us to use the SAXS data from the SeMet-labeled protein for ab initio modeling, which requires a monodisperse sample (Supplementary Fig. S7a). The SAXS-based ab initio model calculated with $D A M M I F$ and the monomeric structure of SeMet-labeled EspG $_{3 \mathrm{msm}}$ (PDB ID 4L4W) are in a good agreement (normalized spatial discrepancy $(\mathrm{NSD})=1.1)$.

The SAXS profiles of the native form of $\mathrm{EspG}_{5 \mathrm{mtu}}$, the only member of the $\mathrm{EspG}_{5}$ family that was analyzed, do not show any concentration dependence over the measured range ( 0.9 to $6.7 \mathrm{mg} / \mathrm{mL}$ ) (Table 3). The constant molecular mass estimates suggest that $\mathrm{EspG}_{5 \mathrm{mtu}}$ is monomeric in solution. We used the program $C R Y S O L$ to fit the theoretical scattering profile based on the crystal structure of the $\mathrm{EspG}_{5 \mathrm{mtu}}$ monomer from the $\mathrm{EspG}_{5 \mathrm{mtu}}-\mathrm{PE} 25$ PPE41 structure (PDB ID 4KXR) to the experimental SAXS data. A significant misfit was observed in the range of momentum transfer of $1.8-2.0 \mathrm{~nm}^{-1}$ (Fig. 5a). In order to evaluate whether flexibility of the $\mathrm{EspG}_{5 \mathrm{mtu}} \beta 2-\beta 3$ loop $\left(\mathrm{Gly}^{92}-\mathrm{Asn}^{114}\right)$ might cause this discrepancy, we employed molecular dynamics (MD) simulations to assign flexible amino acid residues and ensemble optimization method (EOM) to fit the measured SAXS data. The amino acid residue Root-Mean-Square-Fluctuations (RMSF) monitored during a $2 \mathrm{~ns}$ production run indicated high flexibility of the $\beta 2-\beta 3$ loop region and other shorter loop segments (Fig. 5b). Thus, we introduced flexibility in all loop regions of EspG $\mathrm{G}_{5}$ with the program EOM and also modeled the 24 amino acid residues that were missing from the crystallographic structure (Fig. 5c). In the EOM approach, the scattering profile is fitted by a linear combination of scattering profiles from several structural models co-existing in solution. The resulting EOM models where the flexible $\beta 2-\beta 3$ loop exhibits the largest conformational changes compared to the crystallographic structure provide an excellent fit with the experimental SAXS data (Fig. 5a) $\left(\chi^{2}=0.99\right)$. In contrast to the original crystallographic structure in which the $\beta 2-\beta 3$ loop interacts with the PE-PPE heterodimer in an extended conformation, all the EOM structures of EspG $\mathrm{G}_{5 \mathrm{mtu}}$ in solution have more compact forms. More specifically, the $\beta 2-\beta 3$ loop of $\mathrm{EspG}_{5 \mathrm{mtu}}$ folds closely onto the protein core in the SAXS-refined solution structures (Fig. 5c). In addition, the monodisperse EspG $_{5 \mathrm{mtu}}$ SAXS data were employed for ab initio modeling using DAMMIF 
(Supplementary Fig. S7b). The structural alignment yielded a NSD value of 0.93 indicating excellent agreement.

Taken together, these data show clear differences in the oligomerization trends of each EspG ortholog from different ESX systems, indicating that this could be another level of system specificity involved in the secretion of PE-PPE proteins via ESX systems.

\section{Model of the EspG F $_{3}$-PE5-PPE4 trimer structure adopts an extended conformation}

To further analyze substrate recognition by different EspG proteins, we measured solution scattering of EspG ${ }_{3}-\mathrm{PE} 5-\mathrm{PPE} 4$ and EspG 5 -PE25-PPE41 complexes from M. tuberculosis. Model-free parameters derived from the SAXS data indicate that $\mathrm{EspG}_{3 \mathrm{msm}}-\mathrm{PE5}-\mathrm{PPE} 4$ has a more extended open overall conformation $\left(D_{\max }=14.5 \mathrm{~nm} / R_{g}=4.25 \mathrm{~nm}\right)$ than the crystallographic structure of the EspG $\mathrm{Fmtu}-\mathrm{PE} 25-\mathrm{PPE} 41$ complex $\left(D_{\max }=13.0 \mathrm{~nm} / R_{g}=\right.$ $3.93 \mathrm{~nm}$ ) (Fig. 6a). Ab initio modeling in $P 1$ symmetry using SAXS data provided independent information about the overall shapes. The $\mathrm{EspG}_{3 \mathrm{msm}}$ complex reveals a more open structure than the EspG ${ }_{5 \mathrm{mtu}}$ complex, which is consistent with the model-free parameters. In addition, the overall shape of the $\mathrm{EspG}_{5 \mathrm{mtu}}$ complex ab initio structure is in agreement with the crystallographic structure showing a compact structure (PDB ID 4KXR; $\mathrm{NSD}=1.7$, data not shown). The theoretical scattering of the crystallographic structure of the EspG $_{5 \mathrm{mtu}}-\mathrm{PE} 25-\mathrm{PPE} 41$ complex fits the measured SAXS data very well $\left(\chi^{2}=0.95\right)$ (Fig. 6b). This indicates that, in solution, the EspG ${ }_{5 m t u} \beta 2-\beta 3$ loop is in the extended conformation seen in the crystal structure of the EspG $_{5 \mathrm{mtu}}-\mathrm{PE} 25-\mathrm{PPE} 41$ heterotrimer. Thus, the SAXS data for EspG $\mathrm{Fmtu}_{5 \mathrm{tu}}$ alone and in complex with PE25-PPE41 indicates that the $\beta 2$ $\beta 3$ loop undergoes a significant conformational change upon binding.

In order to produce an atomic rigid body model of the $\mathrm{EspG}_{3 \mathrm{msm}}-\mathrm{PE} 5$-PPE4 complex, 300 decoy structures were generated using a molecular docking approach [35] and the crystallographic $\mathrm{EspG}_{3 \mathrm{msm}}$ (PDB ID 4L4W, chain B) structure together with homology models of a complex of full length PE5 and the N-terminal domain of PPE4 (residues 1178) from M. smegmatis generated with SWISS-MODEL [36]. The decoy structures were then ranked by the goodness-of-fit values of their theoretical scattering compared to the experimental scattering data. Fourteen complex structures were selected for further analysis on the basis of their $\mathrm{chi}^{2}$-values $\left(\chi^{2}<1.7\right)$. In addition, all structures had acceptable fits according to $p$-values provided by the correlation map approach [37]. A representative model with the lowest $\chi^{2}$-value was selected for the comparison with the $E_{5 p G} \mathrm{mtu}-\mathrm{PE} 25$ PPE41 complex (Fig. 6b-d).

Comparison of the crystallographic structure of $\mathrm{EspG}_{5 \mathrm{mtu}}-\mathrm{PE} 25-\mathrm{PPE} 41$ (PDB ID 4KXR, [26]) and the SAXS-based rigid-body model of $\mathrm{EspG}_{3 \mathrm{msm}}-\mathrm{PE} 5-\mathrm{PPE} 4$ shows similarities in the binding interfaces of the two complexes, but also significant differences related to the overall binding orientation (Fig. 6c). As expected, the interface between $\mathrm{EspG}_{3 \mathrm{msm}}$ and the PE5- PPE4 heterodimer was found to be mostly comprised of hydrophobic amino acid residues allowing interaction with the hh-motif of PPE4 [26] (Fig. 6d). Analogous to the EspG $_{5 \mathrm{mtu}}-\mathrm{PE} 25-\mathrm{PPE} 41$ complex, the loop between helices a 4 and a 5 of PPE4 (Ala ${ }^{125}$ $1 \mathrm{Ie}^{134}$ ) interacts with the central $\beta$-sheet of $\mathrm{EspG}_{3}$. The structure suggests a hydrogen bonding network between $\mathrm{EspG}_{3}$ and PPE4 formed by several hydrophobic, polar and 
charged amino acid residues Trp27, Glu196, Glu211, Ser215 of EspG $3 \mathrm{msm}_{\text {m }}$ and residues Thr126, Phe128, Gly130, Asn132, Thr133, Ile134 of PPE4 from M. smegmatis. To validate our SAXS model and the interface of $\mathrm{EspG}_{3 \mathrm{msm}}$ and PPE4 in particular, we constructed two mutants of $\mathrm{EspG}_{3 \mathrm{msm}}$ : E196R and S215Y. Substitution E196R reverses the charge of a conserved $\mathrm{E} 196$ residue in the $\mathrm{EspG}_{3}$ orthologs, whereas mutation S215Y introduces a bulky residue that would sterically prevent binding of PPE4. Pull-down experiments showed that E196R and S215Y variants of EspG 3 msm could not bind PE5-PPE4 dimers (Supplementary Fig. S8). Based on the SAXS data and models, we suggest that the more open and flexible structure of $\mathrm{EspG}_{3}-\mathrm{PE} 5-\mathrm{PPE} 4$ is due to differences in the $\mathrm{EspG}_{3} \beta 2-\beta 3$ loop region. The EspG $_{5 \mathrm{mtu}} \beta 2-\beta 3$ loop is comprised of 23 amino acid residues $\left(\mathrm{Gly}^{92}-\mathrm{Asn}^{114}\right)$ and its interaction with PE25-PPE41 forms an extended interface extending from the central $\beta$ sheet of EspG ${ }_{5 \mathrm{mtu}}$. However, the homologous loop region in the $\mathrm{EspG}_{3 \mathrm{msm}}$ structure is significantly shorter (12 amino acid residues; $\mathrm{Val}^{87}$ to $\mathrm{Leu}^{98}$ ) thus an analogous interaction is missing in the $\mathrm{EspG}_{3 \mathrm{msm}}-\mathrm{PE}$-PPE4 rigid-body model. Given that ESX-5 is the major secretion system for export of PE/PPE proteins [22-24, 32], the length and flexibility of the EspG $_{5 \mathrm{mtu}} \beta 2-\beta 3$ loop could be an important structural feature allowing $\mathrm{EspG}_{5 \mathrm{mtu}}$ to interact specifically with many different PE-PPE heterodimers.

\section{Conclusions}

Transport of multiple proteins across the mycobacterial cell envelope is facilitated by the ESX system and cytoplasmic EspG chaperones [38]. However, the precise recognition mechanism of the cognate substrates by ESX system-specific chaperones is not yet fully understood. In this work we present structural analyses of $\mathrm{EspG}_{1}, \mathrm{EspG}_{3}$ and $\mathrm{EspG}_{5}$ and their complexes with PE-PPE secretion substrates using a combination of experimental and in silico methods. The solution scattering data together with novel X-ray crystallographic structures allows us to hypothesize about the substrate specificity of EspG chaperones and provides insight into chaperone-substrate binding mechanisms. This study demonstrates that the $\beta 2-\beta 3$ loop of EspG plays an important role in PE-PPE binding and is a major differentiation factor between the EspG chaperones of orthologous ESX secretion systems. Our results also suggest that EspG dimerization may play a role in substrate recognition.

\section{Materials and methods}

\section{Cloning, expression and purification of $M$. kansasii $E_{s p G_{1}}$}

The DNA sequence corresponding to the full-length $\mathrm{EspG}_{1 \mathrm{mka}}$ was PCR amplified using primers G1mka_F1Nde， 5'-GATACATATGACCGGTCCGCTCGCTAC and G1mka_R283Hind, 5' -CTCAAGCTTAGCCTCGGGCGGAGGCTTG, and genomic DNA of $M$. kansasii ATCC 12478.

The PCR product was digested with NdeI/HindIII and ligated into the corresponding sites of a modified pET-28b vector to create an $\mathrm{N}$-terminal His $_{6}$-tag with a tobacco etch virus (TEV) cleavage site. In efforts to optimize initial crystals, the Cys114Ala and Cys170Ala mutations were introduced using the QuikChange protocol (Stratagene). A truncated DNA fragment corresponding to residues 17-271 was PCR amplified using primers G1mka_F17NCO， 5' GATTCCATGGTCGGCGTCGAGGTCACC and G1mka_R271Hind, 5' -

CTCAAGCTTCAATCTAACCAGGAGCCCGC and cloned into a pET-based vector containing an N- 
terminal $\mathrm{His}_{6}{ }_{-}$-tag followed by a TEV cleavage site and T4L sequence (residues 2-162). The T4L sequence corresponds to a cysteine-less variant with Cys54Thr and Cys97Ala mutations [39, 40]. T4L-EspG $1 \mathrm{mka}$ was expressed in E. coli Rosetta2(DE3) cells in LB supplemented with $50 \mu \mathrm{g} \mathrm{mL} L^{-1}$ kanamycin and $34 \mu \mathrm{g} \mathrm{mL}{ }^{-1}$ chloramphenicol. Cells were grown at $37^{\circ} \mathrm{C}$ and expression was induced with $0.5 \mathrm{mM}$ IPTG at $A_{600}$ of 0.6. Cells were harvested by centrifugation after $3 \mathrm{~h}$, resuspended in lysis buffer $(20 \mathrm{mM}$ Tris- $\mathrm{HCl} \mathrm{pH} 8.5$, $300 \mathrm{mM} \mathrm{NaCl}, 10 \mathrm{mM}$ imidazole) and lysed using an EmulsiFlex C5 homogenizer (Avestin). EspG $_{3 \mathrm{msm}}$ was purified via Ni-NTA metal affinity chromatography. The $\mathrm{His}_{6}$-tag was cleaved using TEV protease followed by a second Ni-NTA purification step to remove uncleaved T4L-EspG ${ }_{1 \mathrm{mka}}$ and $\mathrm{His}_{6}$-tagged TEV protease. Size-exclusion chromatography was performed using a Superdex 200 column (GE Biosciences) equilibrated in buffer containing $20 \mathrm{mM}$ HEPES pH 7.5, $300 \mathrm{mM} \mathrm{NaCl}$.

\section{Crystallization and structure solution of T4L-EspG $\mathbf{1}_{1 \mathrm{mka}}$}

Crystals of T4L-EspG $\mathrm{F}_{1 \mathrm{mka}}$ were obtained by the hanging drop vapor diffusion method using crystallization solution containing 0.1 M Bicine pH 9.0, 1.0 M LiCl, 10\% PEG6000. The crystals were cryoprotected in crystallization solution supplemented with $20 \%$ glycerol and flash cooled in liquid nitrogen before data collection. Data were collected at the SER-CAT beamline 22-ID at the Advanced Photon Source, Argonne National Laboratory. Data were processed and scaled using $X D S$ and $X S C A L E$ [41]. $\mathrm{CC}_{1 / 2}$ value of 0.5 for the outer shell was used to determine the resolution [42]. The T4L-EspG ${ }_{1 \mathrm{mka}}$ structure was solved by molecular replacement using Phaser [43], with the T4L structure (PDB 4GBR) [44] and poly- Ala $\mathrm{EspG}_{3 \mathrm{msm}}$ (PDB ID 4L4W) structure as search models. Two copies of T4L$\mathrm{EspG}_{1 \mathrm{mka}}$ were located in the asymmetric unit. Density modification was performed using Parrot [45], and the molecular replacement model was re-built using Buccaneer [46, 47], $A R P / W A R P$ [48] and manual building in Coot [49]. The iterative rounds of refinement and re-building were performed using phenix.refine [50] and Coot. Non-crystallographic symmetry (NCS) restraints were applied throughout the refinement. Statistics for data collection, refinement, and model quality are listed in Table 1.

\section{Cloning, expression, and purification of $\boldsymbol{M}$. marinum EspG $_{3}$}

The gene (MMAR_0548) encoding EspG $_{3 \mathrm{mma}}$ was PCR-amplified from M. marinum M genomic DNA with Phusion DNA polymerase (New England Biolabs) using gene specific primers (MMAR_0548.For, 5'-AACCTGTATTTCCAGAGTATGGAGTCAATGCCCAACG and MMAR_0548.Rev, 5'-ttcgggctttgttagcagttaGGAGGGTTGACTCGAGAAATCT) and was cloned into a modified pET28 vector, pMAPLe4 [51], using the Gibson ISO assembly procedure [52]. The DNA sequence of the construct was verified by DNA sequencing (Genewiz). $\mathrm{EspG}_{3 \mathrm{mma}}$ was expressed from pMAPLe4 as a maltose binding protein (MBP) fusion which was cleaved in vivo from MBP via a tobacco vein mottling virus (TVMV) protease cleavage site situated between the two moieties; a His ${ }_{6}$ affinity tag and a tobacco etch virus (TEV) protease cleavage site is encoded in the linker between the TVMV protease cleavage site and the $\mathrm{N}$-terminus of the target protein. $\mathrm{EspG}_{3 \mathrm{mma}}$ was expressed in E. coli BL21-Gold (DE3) (Agilent Technologies) using Terrific broth media and protein expression was induced with $1 \mathrm{mM}$ IPTG at $18^{\circ} \mathrm{C}$ overnight. Harvested cells were resuspended in lysis buffer (20 mM Tris, pH 8.0, $300 \mathrm{mM} \mathrm{NaCl,10 \%} \mathrm{glycerol,} 10 \mathrm{mM}$ imidazole) supplemented 
with $\beta$-mercaptoethanol ( $2 \mathrm{mM}$ ), DNase I, lysozyme, and Complete protease inhibitor cocktail (Roche) and lysed by sonication. The lysate was centrifuged $(39,000 \mathrm{~g}, 30$ minutes, $4^{\circ} \mathrm{C}$ ) and $\mathrm{EspG}_{3 \mathrm{mma}}$ was purified from the clarified supernatant using Ni-NTA resin (Thermo Fisher Scientific) equilibrated in lysis buffer. The bound protein was eluted with lysis buffer containing $300 \mathrm{mM}$ imidazole and further purified by size exclusion chromatography (SEC) using a HiLoad 16/60 Superdex 75 column (GE Healthcare) equilibrated with $20 \mathrm{mM}$ Tris, $\mathrm{pH} 8.0,300 \mathrm{mM} \mathrm{NaCl}, 10 \%$ glycerol. $\mathrm{EspG}_{3 \mathrm{mma}}$ eluted from the column in a single symmetrical peak which was concentrated to $21.5 \mathrm{mg} \mathrm{mL}^{-1}$ for crystallization screening.

\section{Crystallization and structure determination of EspG $G_{3 m m a}$}

Small crystals of $\mathrm{EspG}_{3 \mathrm{mma}}$ were grown using the hanging drop vapor-diffusion method by mixing $1 \mu \mathrm{L}$ of protein with $0.5 \mu \mathrm{L}$ of reservoir solution $(1.4 \mathrm{M}$ ammonium sulfate, $200 \mathrm{mM}$ lithium sulfate, $60 \mathrm{mM}$ CAPS, $\mathrm{pH}$ 10.5). These small crystals were used to streak seed other drops that had been equilibrated for a week but showed no signs of crystal growth. Large crystals were found in seeded drops with a reservoir solution containing $1.45 \mathrm{M}$ ammonium sulfate, $200 \mathrm{mM}$ lithium sulfate, $70 \mathrm{mM}$ CAPS, pH 10.5 after 5 weeks. For phase determination and cryoprotection crystals were soaked for 30 minutes at room temperature in a solution containing approximately $4 \mathrm{mM}$ platinum potassium thiocyanate, $1.17 \mathrm{M}$ ammonium sulfate, $160 \mathrm{mM}$ lithium sulfate, $56 \mathrm{mM}$ CAPS pH 10.5, and 15.5\% glycerol. Diffraction data were collected at the Advanced Photon Source at Argonne National Laboratory on beamline 24-ID-C. The data were processed with $X D S$ [41], and the structure was solved by single wavelength anomalous dispersion using HKL2MAP [53], in the SHELX suite of programs [54], which determined the position of seven platinum atoms in the $\mathrm{K}_{2} \mathrm{Pt}(\mathrm{SCN})_{6}$-soaked crystal. An initial model was built using $S H E L X E$ [55] which was improved through iterative rounds of manual model building using Coot [49] interspersed with refinement using REFMAC5 [56].

\section{Cloning, expression and purification of $M$. smegmatis $\mathrm{EspG}_{3}$}

The gene msmeg_O622 encoding $\mathrm{EspG}_{3 \mathrm{msm}}$ was PCR amplified from genomic DNA of $M$. smegmatis mc $^{2} 155$ using primers MsmG3_F1Nde, 5' - GAGACATATGGGGCCTAACGCTGTTG,

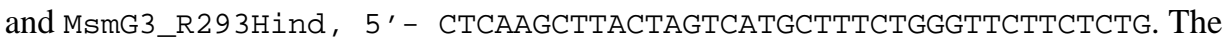
PCR product was digested with NdeI/HindIII and ligated into the corresponding sites of a modified pET-28b vector to create TEV protease-cleavable $\mathrm{N}$-terminal $\mathrm{His}_{6}$-tag fusion. The construct was verified by DNA sequencing (Eurofins Genomics). $\mathrm{EspG}_{3 \mathrm{msm}}$ was expressed and purified using procedures similar to the T4L-EspG $\mathrm{Hmka}_{1 \mathrm{ma}}$ fusion, except the final SEC step was performed in buffer containing $20 \mathrm{mM}$ HEPES pH 7.5, $100 \mathrm{mM} \mathrm{NaCl}$.

\section{Crystallization and structure solution of EspG $\mathbf{G}_{3 \mathrm{msm}}$}

Crystals of $\mathrm{EspG}_{3 \mathrm{msm}}$ in space group $P 3_{2} 21$ were obtained by hanging drop vapor diffusion method with crystallization solutions containing $0.1 \mathrm{M}$ Tris- $\mathrm{HCl} \mathrm{pH}$ 7.0, 0.2 M Mg acetate, $1.8 \mathrm{M} \mathrm{NaCl}$ (SeMet substituted $\mathrm{EspG}_{3 \mathrm{msm}}$ ) and 0.1 M HEPES pH 7.4, $1.0 \mathrm{M} \mathrm{LiCl}, 10 \%$ PEG6000 (native $\mathrm{EspG}_{3 \mathrm{msm}}$ ). Crystals were transferred to crystallization solutions supplemented with 20-25\% glycerol and flash-cooled in liquid nitrogen prior to data 
collection. Data for native and SeMet substituted $\mathrm{EspG}_{3 \mathrm{msm}}$ crystals were collected at the SER-CAT beamline 22-ID at the Advanced Photon Source, Argonne National Laboratory. Data were processed and scaled using $X D S$ and $X S C A L E$ [41]. The $\mathrm{EspG}_{3 \mathrm{msm}}$ structure was solved by SeMet-SAD. The initial selenium positions were found with SHELXD [54] using HKL2MAP interface [53]. Phasing, density modification and initial model building was performed using autoSHARP [57]. A partial model was refined against a native dataset and rebuilt using REFMAC5 [56], ARP/WARP [48] and AutoBuild within PHENIX [58]. The model was completed by iterative rounds of refinement and rebuilding using phenix.refine [50] and Coot [49].

Crystals of SeMet substituted $\mathrm{EspG}_{3 \mathrm{msm}}$ in space group $C 222_{1}$ were grown using crystallization solution containing 0.1 M Tris-HCl pH 8.5, 1.0 M LiCl, 20\% PEG6000. Crystals were transferred into crystallization solution supplemented with $20 \%$ glycerol and flash cooled in liquid nitrogen. The structure was solved by molecular replacement using Phaser [43] with EspG 3 msm (PDB ID 5SXL) structure as a search model. Two EspG 3 msm molecules were located in the asymmetric unit. Following density modification using Parrot [45], the molecular replacement model was rebuilt using Buccaneer [46, 47]. The model was further improved using Coot, $A R P / W A R P$ and AutoBuild within PHENIX. The final model was refined using phenix.refine.

Crystals of $\mathrm{EspG}_{3 \mathrm{msm}}$ in space group $\mathrm{P}_{3} 2_{1} 2$ were grown using crystallization solution containing $0.1 \mathrm{M}$ Na cacodylate $\mathrm{pH}$ 6.0, 15\% PEG200, 5\% PEG3350. The crystals were cryoprotected in solution containing $0.1 \mathrm{M} \mathrm{Na}$ cacodylate $\mathrm{pH}$ 6.0, 35\% PEG200, 5\% PEG3350 and flash cooled in liquid nitrogen. Molecular replacement using Phaser and $\mathrm{EspG}_{3 \mathrm{msm}}$ (PDB ID 4L4W) structure as a search model located 2 molecules in the asymmetric unit. The model was refined using REFMAC5 and rebuilt using AutoBuild within PHENIX. The iterative rounds of refinement and rebuilding were performed using phenix.refine and Coot. NCS restraints were applied in early rounds of refinement and were later omitted as the model quality improved. The last several rounds of refinement were performed using 4 translation/libration/screw (TLS) groups, identified by the TLSMD server $[59,60]$, per protein chain.

\section{Sample preparation for SAXS measurements}

The gene MMAR_5441 encoding EspG $_{1 \mathrm{mma}}$ was PCR amplified from genomic DNA of $M$. marinum E11 using primers DF018, 5' - ATATATAGATCTACCGGTCCGCTCGCTACCGG' , and DF019， 5' - AtATAtAtGCGGCCGCtTAACCTCGGGCGGtGGCGTCG' . The PCR product was digested with BgIII/NotI. The gene MMAR_0548 encoding EspG 3mma $_{3}$ was PCR amplified from genomic DNA of M. marinum E11 using primers DF020, 5' ATATATACCGGTGGAATGGAGTCAATGCCCAACGC' , and DF021, $5^{\prime \prime}-$

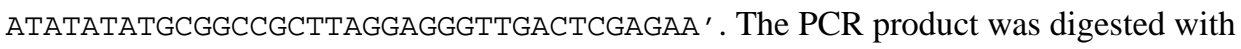
AgeI/NotI. Clones containing genes Rv0289 and Rv1794 encoding EspG $3 \mathrm{mtu}$ and $\mathrm{EspG}_{5 \mathrm{mtu}}$ were further digested with BglII/NotI and AgeI/NotI. Digested fragments were ligated into the corresponding sites of pETM11-SUMO3 to create SENP-2 protease- cleavable Nterminal $\mathrm{His}_{6}$ - $\mathrm{SUMO}_{3}$-tag fusions. 
$\mathrm{His}_{6}-\mathrm{SUMO}_{3}-\mathrm{EspG}_{1 \mathrm{mma}}, \mathrm{His}_{6}-\mathrm{SUMO}_{3}-\mathrm{EspG}_{3 \mathrm{mma}}$, $\mathrm{His}_{6}-\mathrm{SUMO}_{3}-\mathrm{EspG}_{3 \mathrm{mtu}}$ and $\mathrm{His}_{6^{-}}$ $\mathrm{SUMO}_{3}-\mathrm{EspG}_{5 \mathrm{mtu}}$ proteins for SAXS measurements were purified as follows: cells were resuspended in lysis buffer $20 \mathrm{mM}$ HEPES $\mathrm{pH} 7.5,150 \mathrm{mM} \mathrm{NaCl}, 10 \mathrm{mM}$ imidazole, 0.25 $\mathrm{mM}$ tris(2- carboxyethyl)phosphine (TCEP), $10 \%$ (w/v) glycerol (pH 7.5) containing 1/100 protease inhibitor mix HP (Serva), DNAse I $(10 \mu \mathrm{g} / \mathrm{ml})$ and disrupted by lysozyme treatment followed by sonication. The protein was purified via Ni-NTA (Qiagen) affinity chromatography. His6- $\mathrm{SUMO}_{3}$-tag was cleaved by $\mathrm{SenP}_{2}$ protease and further purified using a Phenyl Sepharose HP column (GE Biosciences), followed by SEC using a Superdex 200 16/60 column (GE Biosciences) pre-equilibrated with $20 \mathrm{mM}$ HEPES pH 7.5, $150 \mathrm{mM}$ $\mathrm{NaCl}, 0.25 \mathrm{mM}$ TCEP, $10 \%$ (w/v) glycerol.

The purification procedure for the $\mathrm{EspG}_{5 \mathrm{mtu}}-\mathrm{PE} 25-\mathrm{PPE} 41-\mathrm{His}_{6}$ complex was the same as for the $\mathrm{His}_{6}-\mathrm{SUMO}_{3}$-EspG proteins described above with the exception that the cleavage of the His6 tag was performed by addition of TEV protease. For final aggregated protein removal, the complex was concentrated and injected into a Superdex 200 16/60 size-exclusion chromatography column (GE Biosciences) pre-equilibrated with $20 \mathrm{mM}$ HEPES $\mathrm{pH}$ 7.5, 150 $\mathrm{mM} \mathrm{NaCl}, 0.25 \mathrm{mM}$ TCEP, $10 \%$ (w/v) glycerol. EspG $_{3 \mathrm{msm}}$-PE5-PPE4 complex was obtained as described in [26], and further purified using a Superdex 200 column equilibrated in buffer containing $20 \mathrm{mM}$ HEPES $\mathrm{pH}$ 7.5, $100 \mathrm{mM} \mathrm{NaCl}$. All samples used for SAXS experiments were concentrated to the appropriate protein concentrations ranging from $\sim 1-7$ $\mathrm{mg} \mathrm{ml}^{-1}$.

Mutations E196R and S215Y were introduced into $\mathrm{EspG}_{3 \mathrm{msm}}$ using Gibson mutagenesis protocol and following primers: G3msm_E196R_F5' -

GGTCGGCGCACCTACGTCCGTATCGTCGCGGGCGAGCAT, G3msm_E196R_R5' ATGCTCGCCCGCGACGATACGGACGTAGGTGCGCCGACC, G3msm_S215Y_F5' CACCACCGAGGTGGGGGTCTACATCATCGACACCCCACAC, G3msm_S215Y_R5' GTGTGGGGTGTCGATGATGTAGACCCCCACCTCGGTGGTG, IsoKan_15' GACAATTACAAACAGGAATCGAATGCandIsoKan_25'-GCATTCGATTCCTGTTTGTAATTGTC. The pull-down experiments were performed as described in [26].

\section{SAXS measurements}

SAXS measurements were carried out at beamline P12 (EMBL/DESY, Hamburg) [61] at the PETRA-III storage ring using a Pilatus $2 \mathrm{M}$ detector (Dectris). Measurements for the purified proteins were made at several concentrations (Table 4). For each measurement twenty $50 \mathrm{~ms}$ exposure frames were collected and averaged using a sample volume of $30 \mu \mathrm{l}$ at a temperature of $10^{\circ} \mathrm{C}$. The SAXS camera was set to a sample-detector distance of $3.1 \mathrm{~m}$, covering the momentum transfer range $0.008 \AA-1<s<0.47 \AA^{-1}(s=4 \pi \sin (\theta) / \lambda$ where $2 \theta$ is the scattering angle and $\lambda=1.24 \AA$ is the $\mathrm{X}$-ray wavelength). Prior to and following each sample exposure, a buffer control was measured to allow for background subtraction.

\section{SAXS data analysis using model-free parameters}

Radius of gyration $R_{g}$ and forward scattering intensity $I(0)$, were independently determined using Guinier analysis [62] and the indirect Fourier transformation approach of the program GNOM [63]. Additionally, the maximum particle dimension $D_{\max }$ was obtained from the 
latter approach. Molecular masses of protein constructs (MM $\left.\mathrm{MAXS}_{\mathrm{SAX}}\right)$ were calculated by comparing the extrapolated forward scattering intensities with that of a reference BSA sample $\left(\mathrm{MM}_{\mathrm{ref}}=66 \mathrm{kDa}\right)$ together with concentration information. The excluded volume of the hydrated protein $V p$ was obtained with DATPOROD [64] and used to extract an independent estimate of molecular mass $\left(\mathrm{MM}_{\mathrm{POROD}}\right)$. For globular proteins, hydrated protein volumes in $\AA^{3}$ are approximately 1.7 times the molecular masses in Dalton.

\section{SAXS-based structural modeling}

$A b$ initio models were reconstructed from the scattering data using the simulated annealing based bead-modeling program $D A M M I F[65]$. Ten independent reconstructions were averaged to generate a representative model with the program DAMAVER [66]. In addition, the average $D A M M I F$ ab initio model was used to calculate an excluded volume of the particle, $V_{D A M}$, from which an additional independent MM estimate can be derived (empirically, $M M_{D A M} \sim V_{D A M} / 2$ ). The resolutions of the model ensembles were estimated by a Fourier Shell correlation approach [67].

Theoretical scattering profiles from available high-resolution crystallographic structural models were calculated using the program CRYSOL [68] and used to determine the fit of these models to the experimental scattering data. Given the atomic coordinates of a structural model, CRYSOL minimizes the discrepancy between the experimental and theoretical scattering intensities by adjusting the excluded volume of the particle and the contrast of the hydration layer. Rigid-body modeling was performed using the ZDOCK docking approach [35] to generate decoy structures and complexes were ranked based on their fit to the experimental scattering data.

The scattering profile from a molecular mixture can be decomposed into a linear combination of individual contributions $I_{I}(s)$ from the different species. If the structures of the components are known or their individual scattering profiles can be measured, the volume fractions of the species that fit the SAXS data can be determined by the program OLIGOMER utilizing nonnegative least-squares fitting [69]. Dimeric structures of $\mathrm{EspG}_{3}$ from $M$. tuberculosis and $M$. marinum were generated from their monomeric crystallographic structures (PDB IDs 4W4I and 5DBL, respectively) using the M. smegmatis $\mathrm{EspG}_{3}$ dimer structure (PDB ID 4L4W) as an interaction template. We also used the program OLIGOMER [69] for fitting of experimental scattering profiles of $\mathrm{EspG}_{3 \mathrm{mtu}}$ and $\mathrm{EspG}_{3 \mathrm{mma}}$ by weighted combinations of theoretical scattering profiles from the monomeric crystallographic structures and dimeric models. In the case of $\mathrm{EspG}_{3 \mathrm{msm}}$, theoretical scattering profiles based on the dimeric and monomeric crystallographic structures (PDB ID $4 \mathrm{~L} 4 \mathrm{~W}$ ) were used as inputs for $O L I G O M E R$. For $\mathrm{EspG}_{1 \mathrm{mma}}$, two different dimeric structures were tested: the first dimer structure is based on the structure of the $\mathrm{EspG}_{1 \mathrm{mka}}$ dimer (PDB ID 5VBA) while the second model for a $\mathrm{EspG}_{1 \mathrm{mma}}$ dimer was constructed using the $\mathrm{EspG}_{3 \mathrm{msm}}$ dimer structure (PDB ID 4L4W) as a template.

Flexibility analyses of protein structures in solution were conducted using their crystallographic structures as starting points for the ensemble optimization method (EOM). This approach seeks to best fit the experimental scattering profile with an ensemble of conformations [70, 71]. Possible conformations of loop regions were modeled with the 
program $R A N C H$ producing 10,000 random configurations, while the rest of the protein was kept fixed. A genetic algorithm was employed to find the set of conformations best fitting the SAXS data. The structures selected from the random pool of structures were analyzed with respect to the $R_{g}$ distribution.

\section{Molecular dynamics simulations}

The program NAMD was employed with the CHARMM27 force field for description of the protein and the TIP3P solvent model for water. Constant particle number, constant pressure and constant temperature ( $N p T$ ) ensembles were assumed [72-74]. Langevin dynamics were used to maintain constant temperature. Pressure was controlled using a hybrid Nose-Hoover Langevin piston method. An in-house computational pipeline for high-throughput MD simulations and the visualization program $V M D$ were used to prepare input files and to analyze the simulation trajectories [75].

\section{Supplementary Material}

Refer to Web version on PubMed Central for supplementary material.

\section{Acknowledgements}

We thank Marcel Behr for providing M. kansasii genomic DNA, Wilbert Bitter for providing $M$. marinum genomic DNA and Carlo Carolis for the esp $G_{3 m t u}$ construct. We thank the staff of the UCLA-DOE Institute Protein Expression Technology Center, supported by the U.S. Department of Energy, Office of Biological and Environmental Research (BER) program under Award Number DE-FC02-02ER63421, and the UCLA Crystallization Core for assistance in protein purification and crystallization screening. Authors thank staff members of the Northeastern Collaborative Access Team (NE-CAT) and Southeast Regional Collaborative Access Team (SER-CAT) at the Advanced Photon Source, Argonne National Laboratory, for assistance during data collection. Use of the Advanced Photon Source was supported by the U. S. Department of Energy, Office of Science, Office of Basic Energy Sciences, under Contract No. W-31-109-Eng-38. We acknowledge the Sample Preparation and Characterization (SPC) facility of EMBL at PETRA3 (DESY, Hamburg) for technical support. Work performed in the laboratory of D.E. is supported by the Howard Hughes Medical Institute and National Institutes of Health grants 23616-002-06 F3:02, TBSGC P01 (AI068135), and TBSGC P01 (AI095208). Research reported in this publication was partially supported by an Institutional Development Award (IDeA) from the National Institute of General Medical Sciences of the National Institutes of Health under grant numbers P20GM103486 and P30GM110787, and by the National Institute of Allergy and Infectious Diseases grant number R01AI1 19022 to KVK. A.T.T. was supported by the EMBL EIPOD program under Marie Curie COFUND actions and by the Bundesministerium für Bildung and Forschung (BMBF) project BIOSCAT (grant 05K12YE1).

\section{Abbreviations used:}

EOM

MD

RMSD

NSD

RMSF

SAXS

SEC ensemble optimization method

molecular dynamics

root-mean-square deviation

normalized spatial discrepancy

root-mean-square-fluctuations

small-angle $\mathrm{X}$-ray scattering

size-exclusion chromatography 

SeMet
selenomethionine
TEV
tobacco etch virus
TCEP
tris(2-carboxyethyl)phosphine

\section{References}

[1]. Pai M, Behr MA, Dowdy D, Dheda K, Divangahi M, Boehme CC, et al. Tuberculosis. Nat Rev Dis Primers 2016;2:16076. [PubMed: 27784885]

[2]. Cole ST. Inhibiting Mycobacterium tuberculosis within and without. Philosophical transactions of the Royal Society of London Series B, Biological sciences 2016;371.

[3]. Stanley SA, Raghavan S, Hwang WW, Cox JS. Acute infection and macrophage subversion by Mycobacterium tuberculosis require a specialized secretion system. Proc Natl Acad Sci U S A 2003;100:13001-6. [PubMed: 14557536]

[4]. Lewis KN, Liao R, Guinn KM, Hickey MJ, Smith S, Behr MA, et al. Deletion of RD1 from Mycobacterium tuberculosis mimics bacille Calmette-Guerin attenuation. J Infect Dis 2003;187:117-23. [PubMed: 12508154]

[5]. Guinn KM, Hickey MJ, Mathur SK, Zakel KL, Grotzke JE, Lewinsohn DM, et al. Individual RD1region genes are required for export of ESAT-6/CFP-10 and for virulence of Mycobacterium tuberculosis. Mol Microbiol 2004;51:359-70. [PubMed: 14756778]

[6]. Houben EN, Korotkov KV, Bitter W. Take five - Type VII secretion systems of Mycobacteria. Biochim Biophys Acta 2014;1843:1707-16. [PubMed: 24263244]

[7]. Groschel MI, Sayes F, Simeone R, Majlessi L, Brosch R. ESX secretion systems: mycobacterial evolution to counter host immunity. Nat Rev Microbiol 2016;14:677-91. [PubMed: 27665717]

[8]. Houben EN, Bestebroer J, Ummels R, Wilson L, Piersma SR, Jimenez CR, et al. Composition of the type VII secretion system membrane complex. Mol Microbiol 2012;86:472-84. [PubMed: 22925462]

[9]. Beckham KS, Ciccarelli L, Bunduc CM, Mertens HD, Ummels R, Lugmayr W, et al. Structure of the mycobacterial ESX-5 type VII secretion system membrane complex by single-particle analysis. Nat Microbiol 2017;2:17047. [PubMed: 28394313]

[10]. van Winden VJ, Ummels R, Piersma SR, Jimenez CR, Korotkov KV, Bitter W, et al. Mycosins Are Required for the Stabilization of the ESX-1 and ESX-5 Type VII Secretion Membrane Complexes. mBio 2016;7.

[11]. Cole ST, Brosch R, Parkhill J, Garnier T, Churcher C, Harris D, et al. Deciphering the biology of Mycobacterium tuberculosis from the complete genome sequence. Nature 1998;393:537-44. [PubMed: 9634230]

[12]. Abdallah AM, Gey van Pittius NC, Champion PA, Cox J, Luirink J, Vandenbroucke- Grauls CM, et al. Type VII secretion--mycobacteria show the way. Nat Rev Microbiol 2007;5:883-91. [PubMed: 17922044]

[13]. Gey van Pittius NC, Sampson SL, Lee H, Kim Y, van Helden PD, Warren RM. Evolution and expansion of the Mycobacterium tuberculosis PE and PPE multigene families and their association with the duplication of the ESAT-6 (esx) gene cluster regions. BMC evolutionary biology 2006;6:95. [PubMed: 17105670]

[14]. Strong M, Sawaya MR, Wang S, Phillips M, Cascio D, Eisenberg D. Toward the structural genomics of complexes: crystal structure of a PE/PPE protein complex from Mycobacterium tuberculosis. Proc Natl Acad Sci U S A 2006;103:8060-5. [PubMed: 16690741]

[15]. Delogu G, Brennan MJ. Comparative immune response to PE and PE_PGRS antigens of Mycobacterium tuberculosis. Infect Immun 2001;69:5606-11. [PubMed: 11500435]

[16]. Brennan MJ, Delogu G, Chen Y, Bardarov S, Kriakov J, Alavi M, et al. Evidence that mycobacterial PE_PGRS proteins are cell surface constituents that influence interactions with other cells. Infect Immun 2001;69:7326-33. [PubMed: 11705904] 
[17]. Banu S, Honore N, Saint-Joanis B, Philpott D, Prevost MC, Cole ST. Are the PE-PGRS proteins of Mycobacterium tuberculosis variable surface antigens? Mol Microbiol 2002;44:9-19. [PubMed: 11967065]

[18]. Li Y, Miltner E, Wu M, Petrofsky M, Bermudez LE. A Mycobacterium avium PPE gene is associated with the ability of the bacterium to grow in macrophages and virulence in mice. Cellular microbiology 2005;7:539-48. [PubMed: 15760454]

[19]. Sayes F, Sun L, Di Luca M, Simeone R, Degaiffier N, Fiette L, et al. Strong immunogenicity and cross-reactivity of Mycobacterium tuberculosis ESX-5 type VII secretion: encoded PE-PPE proteins predicts vaccine potential. Cell Host Microbe 2012;11:352-63. [PubMed: 22520463]

[20]. Fortune SM, Jaeger A, Sarracino DA, Chase MR, Sassetti CM, Sherman DR, et al.Mutually dependent secretion of proteins required for mycobacterial virulence. Proc Natl Acad Sci U S A 2005;102:10676-81. [PubMed: 16030141]

[21]. Sani M, Houben EN, Geurtsen J, Pierson J, de Punder K, van Zon M, et al. Direct visualization by cryo-EM of the mycobacterial capsular layer: a labile structure containing ESX-1-secreted proteins. PLoS Pathog 2010;6:e1000794. [PubMed: 20221442]

[22]. Abdallah AM, Verboom T, Hannes F, Safi M, Strong M, Eisenberg D, et al. A specific secretion system mediates PPE41 transport in pathogenic mycobacteria. Mol Microbiol 2006;62:667-79. [PubMed: 17076665]

[23]. Abdallah AM, Verboom T, Weerdenburg EM, Gey van Pittius NC, Mahasha PW, Jimenez C, et al. PPE and PE_PGRS proteins of Mycobacterium marinum are transported via the type VII secretion system ESX-5. Mol Microbiol 2009;73:329-40. [PubMed: 19602152]

[24]. Bottai D, Di Luca M, Majlessi L, Frigui W, Simeone R, Sayes F, et al. Disruption of the ESX-5 system of Mycobacterium tuberculosis causes loss of PPE protein secretion, reduction of cell wall integrity and strong attenuation. Mol Microbiol 2012;83:1195-209. [PubMed: 22340629]

[25]. Daleke MH, van der Woude AD, Parret AH, Ummels R, de Groot AM, Watson D, et al. Specific chaperones for the type VII protein secretion pathway. J Biol Chem 2012;287:31939-47. [PubMed: 22843727]

[26]. Korotkova N, Freire D, Phan TH, Ummels R, Creekmore CC, Evans TJ, et al. Structure of the Mycobacterium tuberculosis type VII secretion system chaperone EspG5 in complex with PE25PPE41 dimer. Mol Microbiol 2014;94:367-82. [PubMed: 25155747]

[27]. Ekiert DC, Cox JS. Structure of a PE-PPE-EspG complex from Mycobacterium tuberculosis reveals molecular specificity of ESX protein secretion. Proc Natl Acad Sci U S A 2014;111:14758-63. [PubMed: 25275011]

[28]. Daleke MH, Ummels R, Bawono P, Heringa J, Vandenbroucke-Grauls CM, Luirink J, et al. General secretion signal for the mycobacterial type VII secretion pathway. Proc Natl Acad Sci U S A 2012;109:11342-7. [PubMed: 22733768]

[29]. Poulsen C, Panjikar S, Holton SJ, Wilmanns M, Song YH. WXG100 protein superfamily consists of three subfamilies and exhibits an alpha-helical C-terminal conserved residue pattern. PLoS One 2014;9:e89313. [PubMed: 24586681]

[30]. Ramsdell TL, Huppert LA, Sysoeva TA, Fortune SM, Burton BM. Linked domain architectures allow for specialization of function in the FtsK/SpoIIIE ATPases of ESX secretion systems. J Mol Biol 2015;427:1119-32. [PubMed: 24979678]

[31]. Rosenberg OS, Dovala D, Li X, Connolly L, Bendebury A, Finer-Moore J, et al. Substrates Control Multimerization and Activation of the Multi-Domain ATPase Motor of Type VII Secretion. Cell 2015;161:501-12. [PubMed: 25865481]

[32]. Daleke MH, Cascioferro A, de Punder K, Ummels R, Abdallah AM, van der Wel N, et al. Conserved Pro-Glu (PE) and Pro-Pro-Glu (PPE) protein domains target LipY lipases of pathogenic mycobacteria to the cell surface via the ESX-5 pathway. J Biol Chem 2011;286:19024-34. [PubMed: 21471225]

[33]. Phan TH, Ummels R, Bitter W, Houben EN. Identification of a substrate domain that determines system specificity in mycobacterial type VII secretion systems. Sci Rep 2017;7:42704. [PubMed: 28205541] 
[34]. Chen X, Cheng HF, Zhou J, Chan CY, Lau KF, Tsui SK, et al. Structural basis of the PE-PPE protein interaction in Mycobacterium tuberculosis. J Biol Chem 2017;292:16880-90. [PubMed: 28842489]

[35]. Pierce BG, Wiehe K, Hwang H, Kim BH, Vreven T, Weng Z. ZDOCK server: interactive docking prediction of protein-protein complexes and symmetric multimers. Bioinformatics 2014;30:1771-3. [PubMed: 24532726]

[36]. Biasini M, Bienert S, Waterhouse A, Arnold K, Studer G, Schmidt T, et al. SWISS- MODEL: modelling protein tertiary and quaternary structure using evolutionary information. Nucleic Acids Res 2014;42:W252-8. [PubMed: 24782522]

[37]. Franke D, Jeffries CM, Svergun DI. Correlation Map, a goodness-of-fit test for one- dimensional X-ray scattering spectra. Nature methods 2015;12:419-22. [PubMed: 25849637]

[38]. Phan TH, Houben ENG. Bacterial secretion chaperones: the mycobacterial type VII case. FEMS Microbiol Lett 2018;365.

[39]. Matsumura M, Becktel WJ, Levitt M, Matthews BW. Stabilization of phage T4 lysozyme by engineered disulfide bonds. Proc Natl Acad Sci U S A 1989;86:6562-6. [PubMed: 2671995]

[40]. Rosenbaum DM, Cherezov V, Hanson MA, Rasmussen SG, Thian FS, Kobilka TS, et al. GPCR engineering yields high-resolution structural insights into beta2-adrenergic receptor function. Science 2007;318:1266-73. [PubMed: 17962519]

[41]. Xds Kabsch W.. Acta Crystallogr D Biol Crystallogr 2010;66:125-32. [PubMed: 20124692]

[42]. Karplus PA, Diederichs K. Linking crystallographic model and data quality. Science 2012;336:1030-3. [PubMed: 22628654]

[43]. McCoy AJ, Grosse-Kunstleve RW, Adams PD, Winn MD, Storoni LC, Read RJ. Phaser crystallographic software. J Appl Crystallogr 2007;40:658-74. [PubMed: 19461840]

[44]. Zou Y, Weis WI, Kobilka BK. N-terminal T4 lysozyme fusion facilitates crystallization of a G protein coupled receptor. PLoS One 2012;7:e46039. [PubMed: 23056231]

[45]. Cowtan K Recent developments in classical density modification. Acta Crystallogr D Biol Crystallogr 2010;66:470-8. [PubMed: 20383000]

[46]. Cowtan K The Buccaneer software for automated model building. 1. Tracing protein chains. Acta Crystallogr D Biol Crystallogr 2006;62:1002-11. [PubMed: 16929101]

[47]. Cowtan K Fitting molecular fragments into electron density. Acta Crystallogr D Biol Crystallogr 2008;64:83-9. [PubMed: 18094471]

[48]. Langer G, Cohen SX, Lamzin VS, Perrakis A. Automated macromolecular model building for Xray crystallography using ARP/wARP version 7. Nat Protoc 2008;3:1171-9. [PubMed: 18600222]

[49]. Emsley P, Lohkamp B, Scott WG, Cowtan K. Features and development of Coot. Acta Crystallogr D Biol Crystallogr 2010;66:486-501. [PubMed: 20383002]

[50]. Afonine PV, Grosse-Kunstleve RW, Echols N, Headd JJ, Moriarty NW, Mustyakimov M, et al. Towards automated crystallographic structure refinement with phenix.refine. Acta Crystallogr D Biol Crystallogr 2012;68:352-67. [PubMed: 22505256]

[51]. Arbing MA, Chan S, Harris L, Kuo E, Zhou TT, Ahn CJ, et al. Heterologous expression of mycobacterial Esx complexes in Escherichia coli for structural studies is facilitated by the use of maltose binding protein fusions. PLoS One 2013;8:e81753. [PubMed: 24312350]

[52]. Gibson DG. Enzymatic assembly of overlapping DNA fragments. Methods Enzymol2011;498:349-61. [PubMed: 21601685]

[53]. Pape T, Schneider TR. HKL2MAP: a graphical user interface for phasing with SHELX programs. J Appl Cryst 2004;37:843-4.

[54]. Sheldrick GM. A short history of SHELX. Acta Crystallogr A 2008;64:112-22. [PubMed: 18156677]

[55]. Sheldrick GM. Experimental phasing with SHELXC/D/E: combining chain tracing with density modification. Acta Crystallogr D Biol Crystallogr 2010;66:479-85. [PubMed: 20383001]

[56]. Murshudov GN, Skubak P, Lebedev AA, Pannu NS, Steiner RA, Nicholls RA, et al. REFMAC5 for the refinement of macromolecular crystal structures. Acta Crystallogr D Biol Crystallogr 2011;67:355-67. [PubMed: 21460454] 
[57]. Vonrhein C, Blanc E, Roversi P, Bricogne G. Automated structure solution with autoSHARP. Methods Mol Biol 2007;364:215-30. [PubMed: 17172768]

[58]. Adams PD, Afonine PV, Bunkoczi G, Chen VB, Davis IW, Echols N, et al. PHENIX: a comprehensive Python-based system for macromolecular structure solution. Acta Crystallogr D Biol Crystallogr 2010;66:213-21. [PubMed: 20124702]

[59]. Painter J, Merritt EA. Optimal description of a protein structure in terms of multiple groups undergoing TLS motion. Acta Crystallogr D Biol Crystallogr 2006;62:439-50. [PubMed: 16552146]

[60]. Painter J, Merritt EA. TLSMD web server for the generation of multi-group TLS models.J Appl Cryst 2006;39:109-11.

[61]. Blanchet CE, Spilotros A, Schwemmer F, Graewert MA, Kikhney A, Jeffries CM, et al.Versatile sample environments and automation for biological solution X-ray scattering experiments at the P12 beamline (PETRA III, DESY). J Appl Crystallogr 2015;48:431-43. [PubMed: 25844078]

[62]. Guinier A La diffraction des rayons $X$ aux très petits angles : application à l'étude de phénomènes ultramicroscopiques. Ann Phys 1939;11:161-237.

[63]. Svergun DI. Determination of the regularization parameter in indirect-transform methods using perceptual criteria. J Appl Cryst 1992;25:495-503.

[64]. Petoukhov MV, Franke D, Shkumatov AV, Tria G, Kikhney AG, Gajda M, et al. New developments in the ATSAS program package for small-angle scattering data analysis. J Appl Crystallogr 2012;45:342-50. [PubMed: 25484842]

[65]. Franke D, Svergun DI. DAMMIF, a program for rapid ab-initio shape determination in smallangle scattering. J Appl Crystallogr 2009;42:342-6. [PubMed: 27630371]

[66]. Volkov VV, Svergun DI. Uniqueness of ab initio shape determination in small-angle scattering. J Appl Cryst 2003;36:860-4.

[67]. Tuukkanen AT, Kleywegt GJ, Svergun DI. Resolution of ab initio shapes determined from smallangle scattering. IUCrJ 2016;3:440-7.

[68]. Svergun D, Barberato C, Koch MHJ. CRYSOL - a program to pvaluate X-ray solution scattering of biological macromolecules from atomic coordinates. J Appl Cryst 1995;28:768-73.

[69]. Konarev PV, Volkov VV, Sokolova AV, Koch MHJ, Svergun DI. PRIMUS: a Windows PC-based system for small-angle scattering data analysis. J Appl Cryst 2003;36:1277-82.

[70]. Bernado P, Mylonas E, Petoukhov MV, Blackledge M, Svergun DI. Structural characterization of flexible proteins using small-angle X-ray scattering. J Am Chem Soc 2007;129:5656-64. [PubMed: 17411046]

[71]. Tria G, Mertens HD, Kachala M, Svergun DI. Advanced ensemble modelling of flexible macromolecules using X-ray solution scattering. IUCrJ 2015;2:207-17.

[72]. Phillips JC, Braun R, Wang W, Gumbart J, Tajkhorshid E, Villa E, et al. Scalable molecular dynamics with NAMD. J Comput Chem 2005;26:1781-802. [PubMed: 16222654]

[73]. MacKerell AD, Bashford D, Bellott M, Dunbrack RL, Evanseck JD, Field MJ, et al. All- atom empirical potential for molecular modeling and dynamics studies of proteins. J Phys Chem B 1998;102:3586-616. [PubMed: 24889800]

[74]. Jorgensen WL, Chandrasekhar J, Madura JD, Impey RW, Klein ML. Comparison of simple potential functions for simulating liquid water. J Chem Phys 1983;79:926-35.

[75]. Humphrey W, Dalke A, Schulten K. VMD: visual molecular dynamics. J Mol Graph 1996;14:338, 27-8. [PubMed: 8744570]

[76]. Chen VB, Arendall WB, 3rd, Headd JJ, Keedy DA, Immormino RM, Kapral GJ, et al. MolProbity: all-atom structure validation for macromolecular crystallography. Acta Crystallogr D Biol Crystallogr 2010;66:12-21. [PubMed: 20057044] 


\section{Highlights}

- The crystal structure of $\mathrm{EspG}_{1}$ reveals the common architecture of the type VII secretion system chaperones

- Structures of $\mathrm{EspG}_{3}$ chaperones display a number of conformations that could reflect alternative substrate binding modes

- $\mathrm{EspG}_{3}$ chaperones dimerize in solution

- $\quad$ A model of EspG 3 in complex with its substrate PE-PPE dimer is proposed based on SAXS data 
(a)

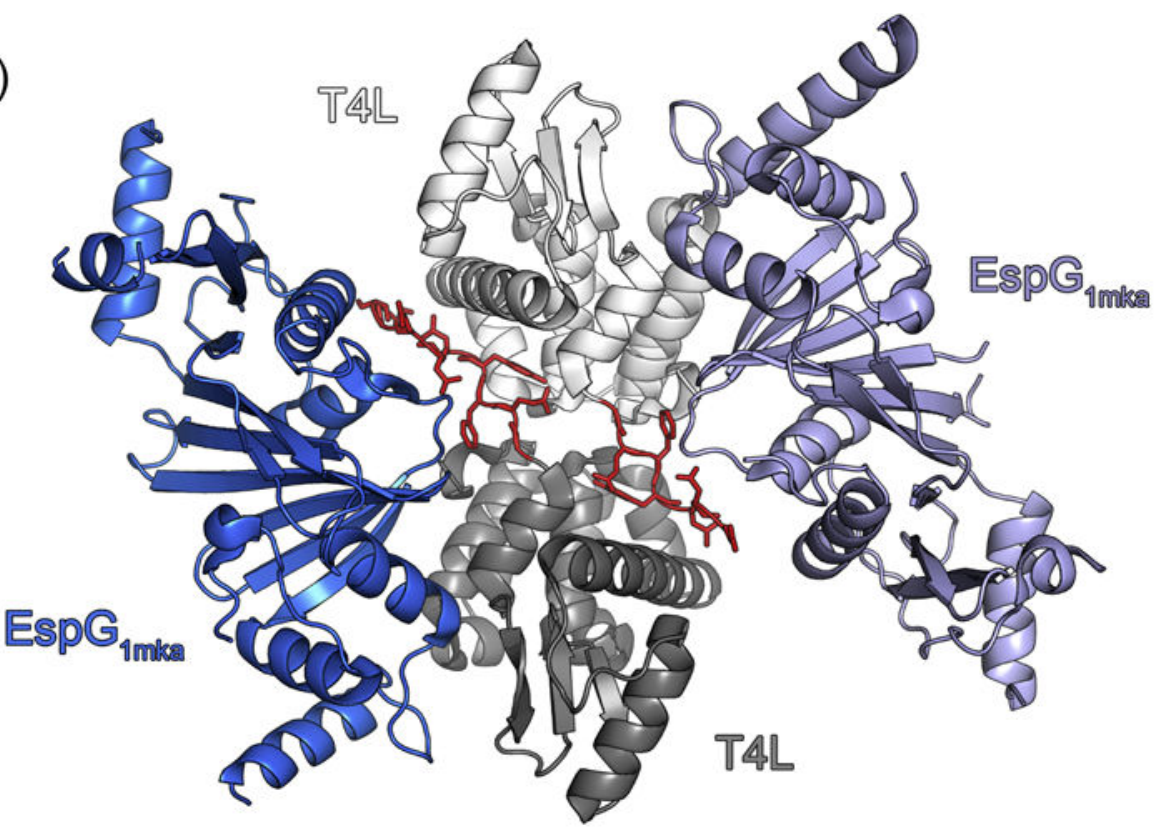

(b)

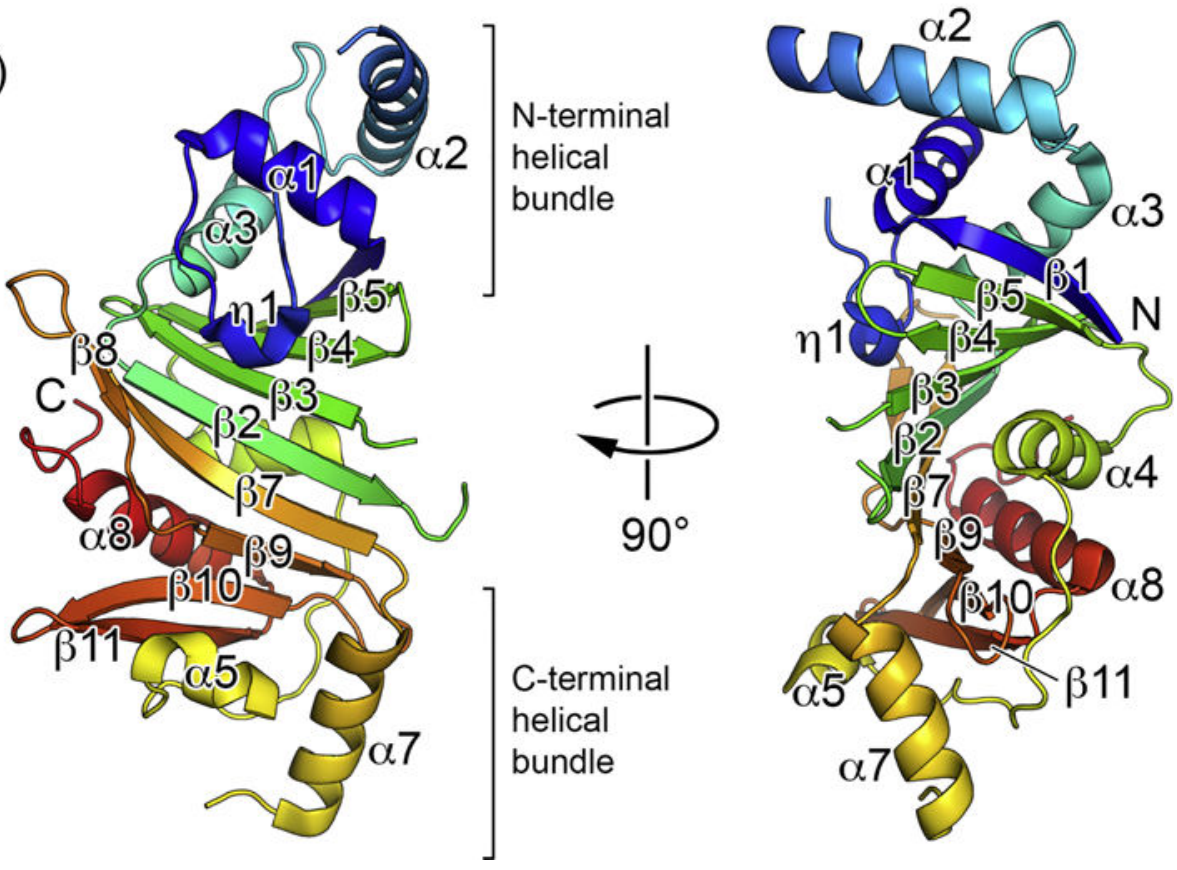

Figure 1. Crystal structure of M. kansasii $\operatorname{EspG}_{1}\left(\operatorname{EspG}_{1 \mathrm{mka}}\right)$.

(a) View of the two subunits of the T4L-EspG 1 mka fusion protein in the asymmetric unit. Chain $A$ is shown in light grey (T4L) and light blue $\left(\mathrm{EspG}_{1 \mathrm{mka}}\right)$, and chain $\mathrm{B}$ is shown in dark grey $(\mathrm{T} 4 \mathrm{~L})$ and dark blue $\left(\mathrm{EspG}_{1 \mathrm{mka}}\right)$. Residues corresponding to the TEV cleavage sequence are shown in red with side chains in stick representation. (b) A monomer of EspG $_{1 \mathrm{mka}}$ is shown in ribbon representation colored in rainbow colors from N-terminus (blue) to C-terminus (red). The $\mathrm{N}$ - terminal T4L fusion moiety is not shown for clarity. 

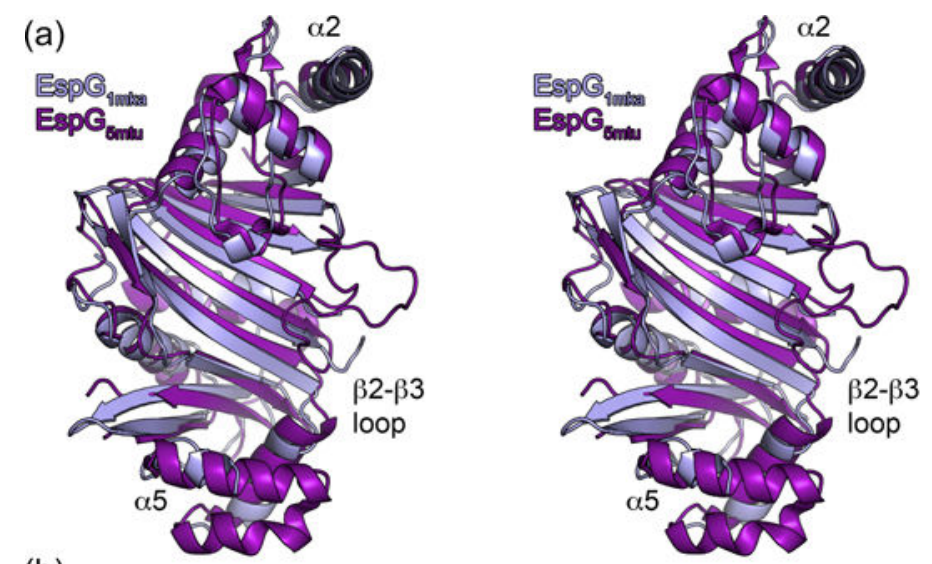

(b)

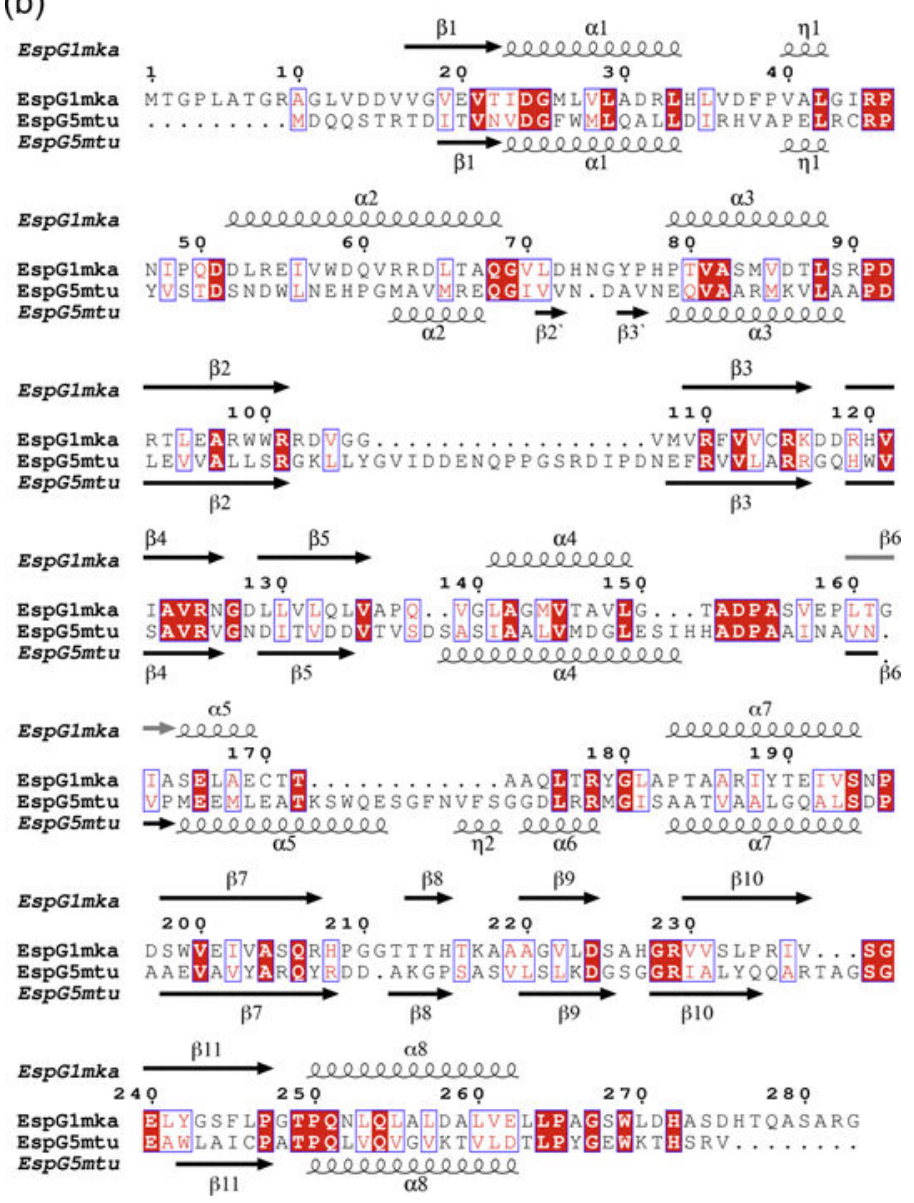

Figure 2. Structural comparison between EspG $_{1 \mathbf{m k a}}$ and $\mathbf{E s p G}_{\mathbf{5 m t u}}$.

(a) Stereo view of superposed EspG $_{1 \mathrm{mka}}$ and EspG $_{5 \mathrm{mtu}}$ crystal structures. The structure of the EspG $_{5 \mathrm{mtu}}$ monomer is derived from the trimeric EspG $_{5 \mathrm{mtu}}-\mathrm{PE} 25-\mathrm{PPE} 41-$ complex (PDB ID 4KXR, [26]). (b) Structure-based sequence alignment of EspG $\mathrm{F}_{1 \mathrm{mka}}$ and EspG $\mathrm{Fmtu}_{5 \mathrm{~m}}$. Secondary structure elements corresponding to the EspG $_{1 \mathrm{mka}}$ structure (PDB ID 5VBA) and EspG $_{5 \mathrm{mtu}}$ structure (PDB ID 4KXR) are displayed above and below the alignment. 
(a)

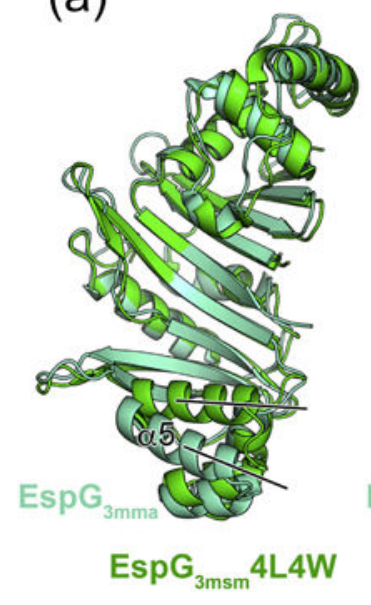

(b)

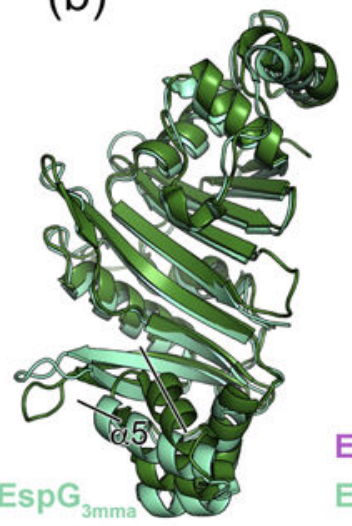

$\mathrm{EspG}_{3 \mathrm{msm}} 5 \mathrm{SXL}$

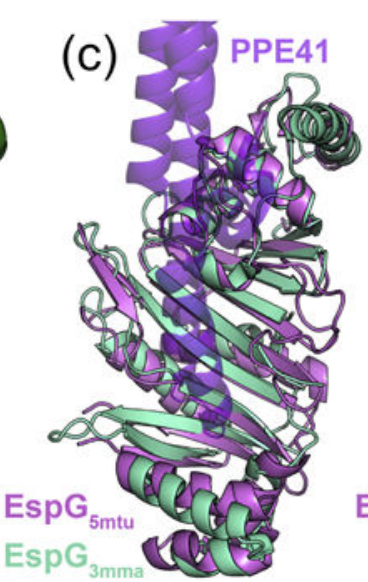

$\mathrm{EspG}_{3 \mathrm{mma}}$ Co

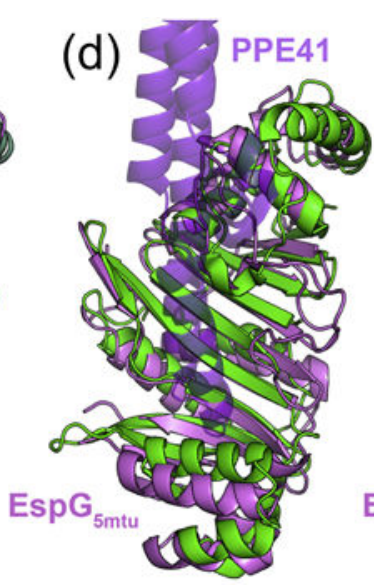

$\mathrm{EspG}_{3 \mathrm{msm}} 4 \mathrm{~L} 4 \mathrm{~W}$

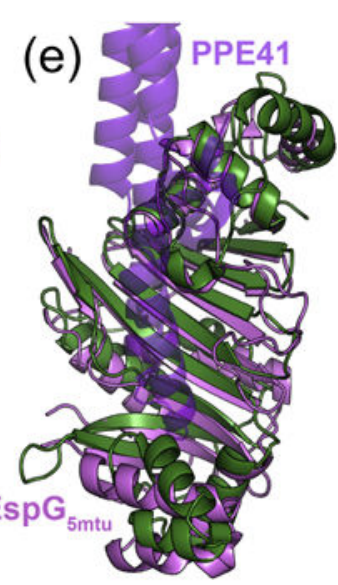

$\mathrm{EspG}_{3 \mathrm{msm}} 5 \mathrm{SXL}$

Figure 3. Crystal structures of EspG 3 chaperones display variations in their putative PE-PPE binding region.

(a) Structural superposition of $\mathrm{EspG}_{3 \mathrm{mma}}$ (aquamarine) and $\mathrm{EspG}_{3 \mathrm{msm}}$ (PDB ID 4L4W, green). Black lines indicate differences in the orientation of the a 5 helix. A stereo version is available as Supplementary Figure 4a. (b) Structural superposition of EspG $3 \mathrm{mma}_{3}$ and EspG $_{3 \mathrm{msm}}$ (PDB ID 5SXL, dark green). A stereo version is available as Supplementary Figure 4b. (c,d,e) Structural superposition of EspG 3 mma, EspG $\mathrm{Emsm}_{3 \mathrm{~m}}$ (PDB ID 4L4W), and $\mathrm{EspG}_{3 \mathrm{msm}}$ (PDB ID 5SXL) with EspG $5 \mathrm{mtu}$ (PDB ID 4W4I [27], violet) derived from the heterotrimeric EspG $_{5 \mathrm{mtu}}$-PE25-PPE41 structure (PDB ID 4KXR [26]). PPE41 (purple) is shown in semi-transparent ribbon representation. PE25 is omitted for clarity as it is not in contact with $\mathrm{EspG}_{5 \mathrm{mtu}}$. Stereo versions of $(\mathrm{c}, \mathrm{d}, \mathrm{e})$ are available as Supplementary Figure 5. 


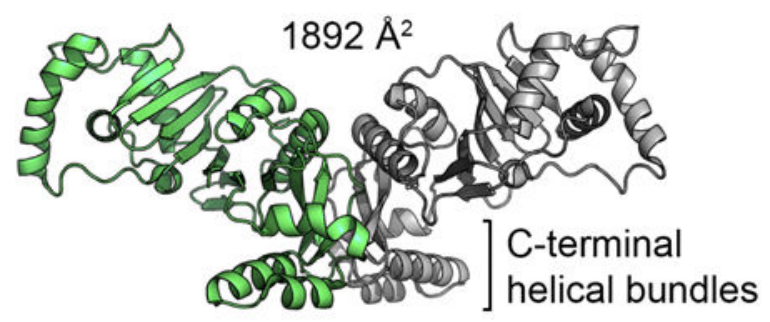

$$
\text { wing-shaped dimer, Esp } \mathrm{G}_{3 \mathrm{msm} 4 \mathrm{~L} 4 \mathrm{~W}}
$$

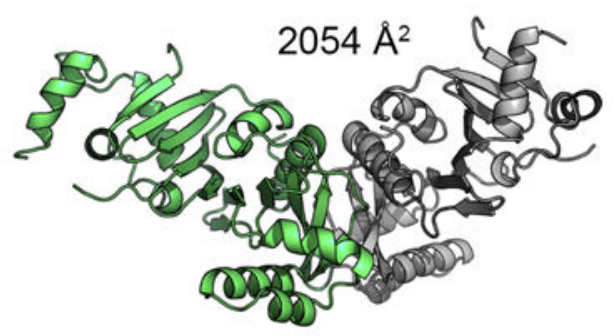

wing-shaped dimer, EspG $G_{3 m s m 4 R C L}$

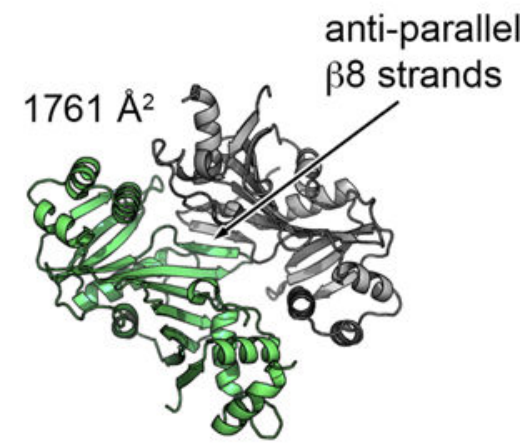

$\beta 8$-mediated dimer, $\mathrm{EspG}_{3 \mathrm{msm} 4 \mathrm{RCL}}$

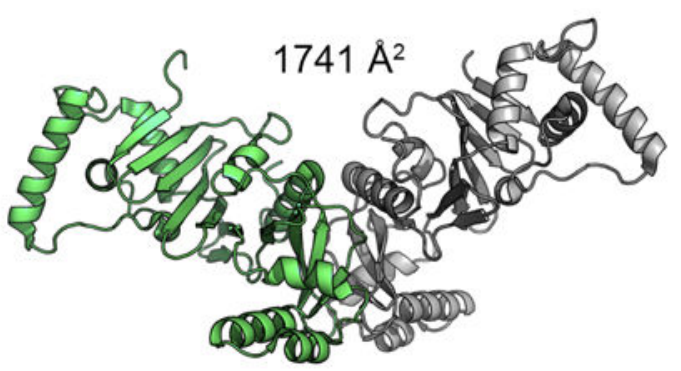

wing-shaped dimer, EspG $\mathrm{G}_{3 \mathrm{msm} 4 \mathrm{~W} 4 \mathrm{~J}}$

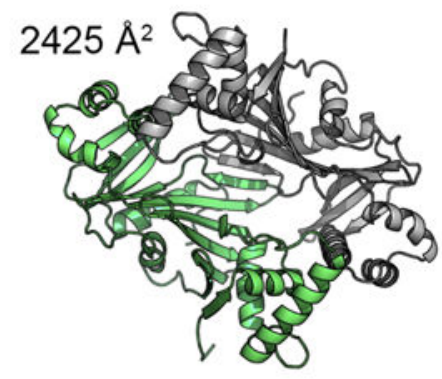

$\beta 8$-mediated dimer, $\mathrm{EspG}_{3 \mathrm{msm} 4 \mathrm{~W} 4 \mathrm{~J}}$

Figure 4. Cartoon representation of the common dimer structures observed in crystal forms of EspG3.

Superimposed subunits are in green with the buried surface area of the dimer interface indicated above the structure. The wing-shaped dimers are present in the asymmetric unit of $\mathrm{EspG}_{3 \mathrm{msm}}\left(\mathrm{PDB}\right.$ ID 4L4W) and $\mathrm{EspG}_{3 \mathrm{msm}}$ (PDB ID 4W4J) or generated by crystallographic symmetry in $\mathrm{EspG}_{3 \mathrm{msm}}$ (PDB ID 4RCL). The $\beta 8$-mediated dimer is present in the asymmetric unit in $\mathrm{EspG}_{3 \mathrm{msm}}$ (PDB ID 4RCL) and generated by crystallographic symmetry in $\mathrm{EspG}_{3 \mathrm{msm}}$ (PDB ID 4W4J [27]). 
(a)

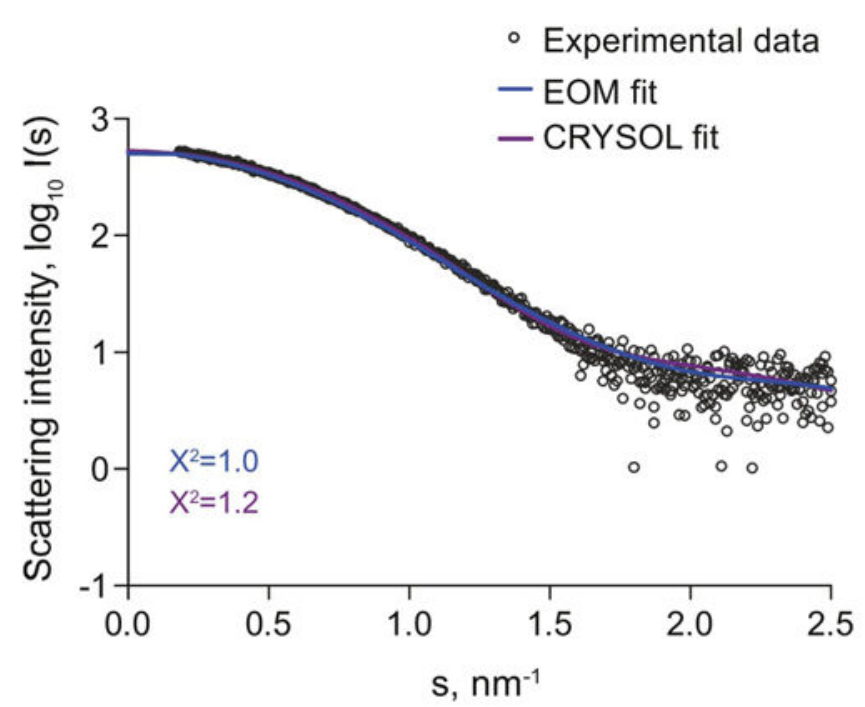

(c)

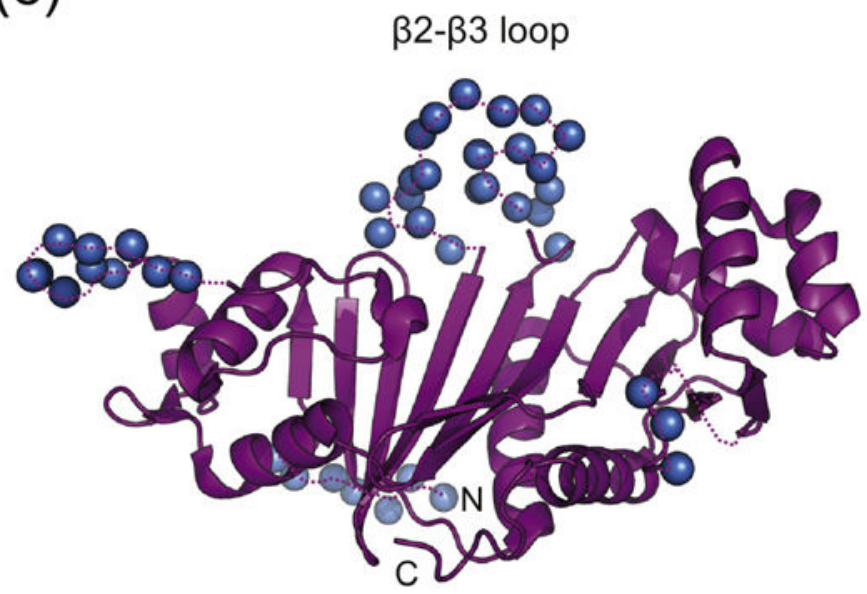

(b)
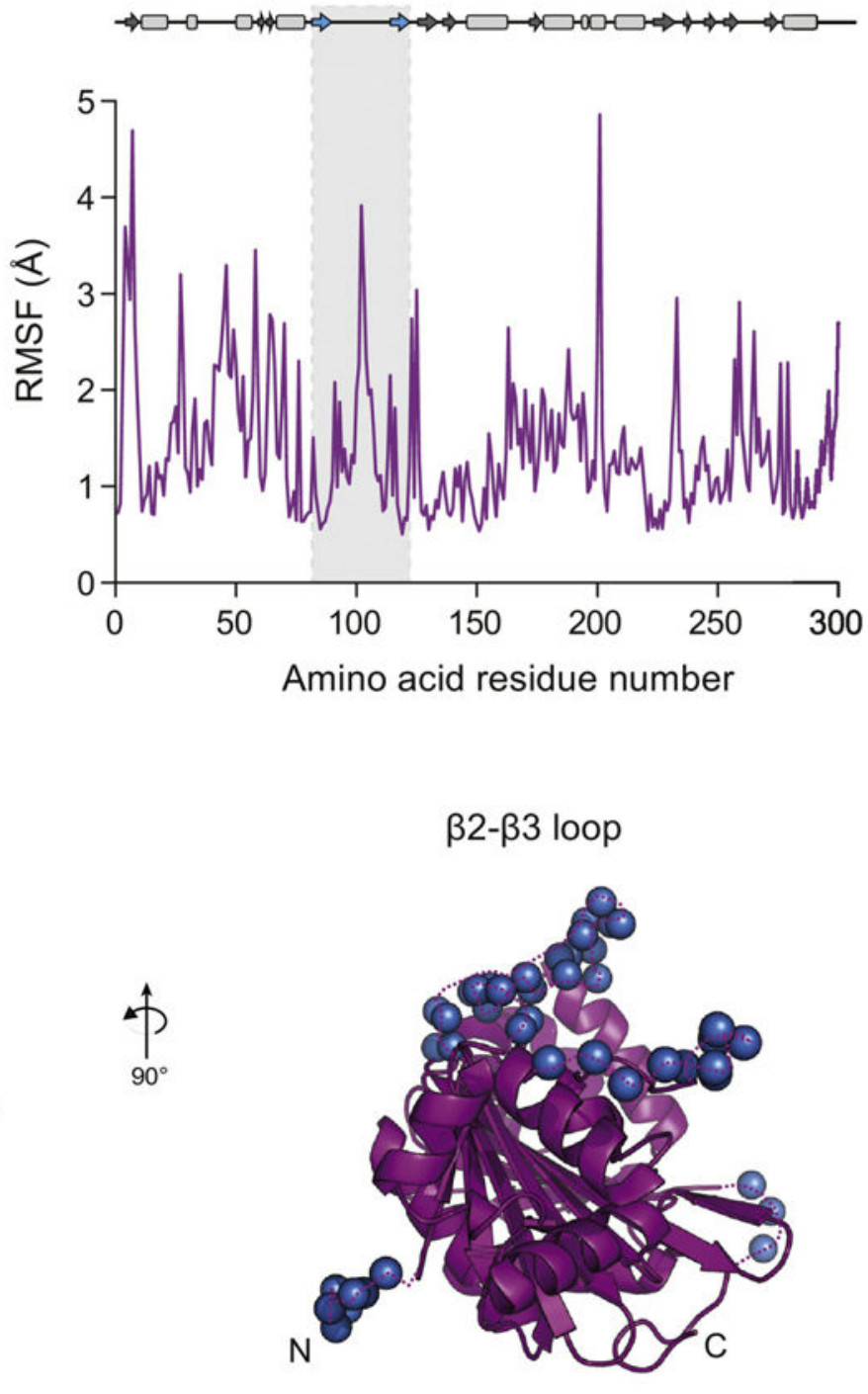

Figure 5. Solution structure of EspG $_{5 \mathrm{mtu}}$ •

(a) Experimental SAXS data (black circles) and computed fits (solid lines) with respective discrepancy values $\left(\chi^{2}\right)$. The theoretical SAXS curve of the EspG $\mathrm{Gm}_{5 \mathrm{~m} u}$ crystal structure when in complex with PE25/PPE41 as calculated using CRYSOL (purple) (PDB ID 4KXR, chain C) fits the experimental SAXS data with a $\chi^{2}$ of 1.2 and an apparent misfit around $s=1.8-$ $2.0 \mathrm{~nm}^{-1}$. To calculate the EOM fit, the 24 amino acid residues that were missing from the crystallographic structure of EspG $\mathrm{Smtu}_{5 \mathrm{~m}}$ were added at the N-terminus and flexibility of all loops was allowed. This procedure resulted in an improvement of the fit to a $\chi^{2}$ value of 0.99 (blue). (b) The amino acid residue root-mean- square-fluctuation (RMSF) of EspG $\mathrm{Gmtu}_{5 \mathrm{u}}$ (starting structure PDB ID 4KXR, chain C) during a molecular dynamics simulation run. The secondary structure assignment of the crystallographic structure is shown above the RMSF plot for reference, where $\beta$-sheets and $\alpha$-helices are represented by arrows and rectangles, respectively. (c) The flexible loop regions and the amino acid residues missing 
from the crystallographic structure of $\mathrm{EspG}_{5 \mathrm{mtu}}$ crystal structure when in complex with PE25-PPE41 (purple) are modeled as dummy residues (blue spheres). 
(a)

(c)

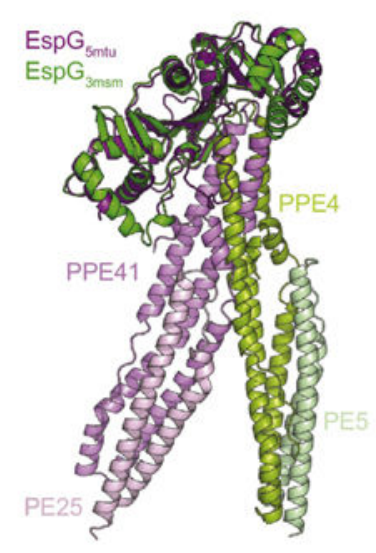

$\mathrm{EspG}_{\text {5mut }}$-PE25-PPE41

$D_{\text {max }}=13.0 \mathrm{~nm}$

$\mathrm{R}_{\mathrm{g}}=3.93 \mathrm{~nm}$

EspG $_{3 \mathrm{mmm}}$-PE5-PPE4

$\mathrm{D}_{\max }=14.5 \mathrm{~nm}$

$\mathrm{R}_{\mathrm{g}}=4.25 \mathrm{~nm}$ (b)

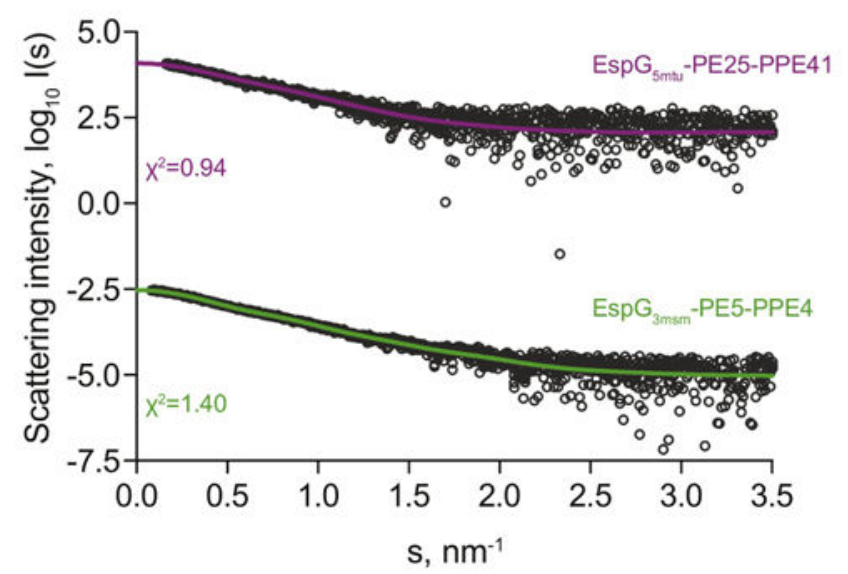

(d)

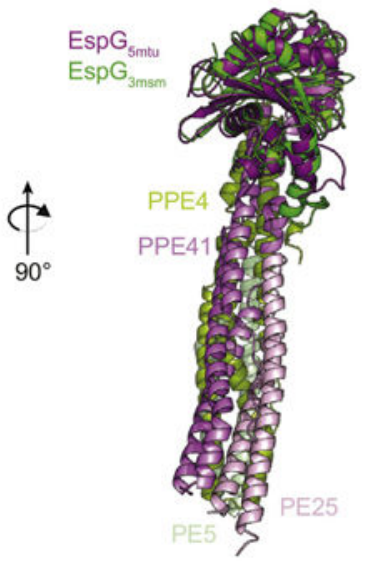

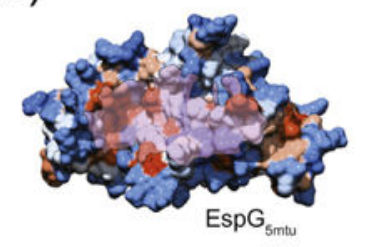
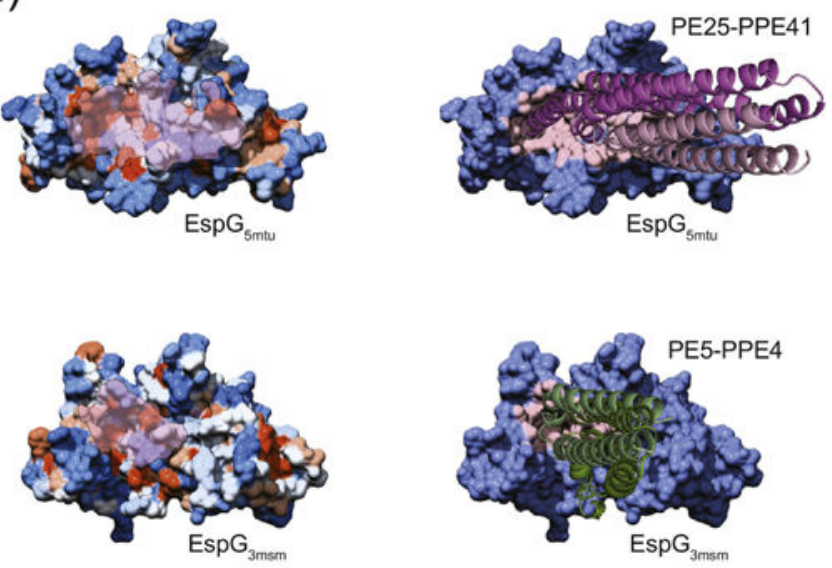

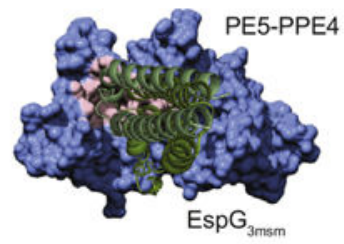

Figure 6. Comparison of EspG 5 -PE25-PPE41 and EspG 3 -PE5-PPE4 ${ }^{1-178}$ complexes structures. (a) SAXS-based ab initio models of the EspG $_{5 \mathrm{mtu}}$-PE25-PPE41 complex (purple) and the EspG $_{3 \mathrm{msm}}$-PE5-PPE4 ${ }^{1-178}$ complex (green) reveal a more extended conformation of the EspG $_{3 \mathrm{msm}}$-PE5-PPE4 ${ }^{1-178}$ complex, as indicated by the maximum diameter $\left(D_{\max }\right)$ and radius of gyration $\left(R_{g}\right)$ of each complex. (b) Experimental SAXS data (black circles) with the computed fits (solid lines) and the respective discrepancy values $\left(\chi^{2}\right)$ for $\mathrm{EspG}_{5 \mathrm{mtu}}{ }^{-}$ PE25- PPE41 and EspG $3 \mathrm{msm}$-PE5-PPE4 protein complexes. The theoretical SAXS curve, calculated with CRYSOL from the EspG $_{5 \mathrm{mtu}}$-PE25-PPE41 complex structure (PDB ID $4 \mathrm{KXR}$ ), fits the experimental SAXS data with a goodness-of-fit ( $\left.\chi^{2}\right)$ of 0.95 (purple). The theoretical SAXS curve calculated from the $\mathrm{EspG}_{3 \mathrm{msm}}$ rigid-body model in complex with a homology model of PE5-PPE4 ${ }^{1-178}$ fits the experimental SAXS data (green) with a goodness- of-fit values $\left(\chi^{2}\right)$ of 1.40 . (c) Superposition of the crystal structure of EspG $\mathrm{mmtu}^{-}$ PE25-PPE41 (purple-lilac-light pink) and the SAXS-derived rigid body model of $\mathrm{EspG}_{3 \mathrm{msm}^{-}}$ PE5-PPE4 ${ }^{1-178}$ (dark green-light green-light blue). (d) Hydrophobicity surface representation of EspG proteins with PPE-interacting surface highlighted in transparent pink (left panel). Interaction interface of EspG $5 \mathrm{mtu}-\mathrm{PPE} 41$ and $\mathrm{EspG}_{3 \mathrm{msm}}-\mathrm{PPE} 4$, with PPE-PE 
proteins represented as cartoon and EspG proteins as surface with the contact residues in the interface colored in light pink in each EspG protein (right panel). 


\section{롤 \\ 골}

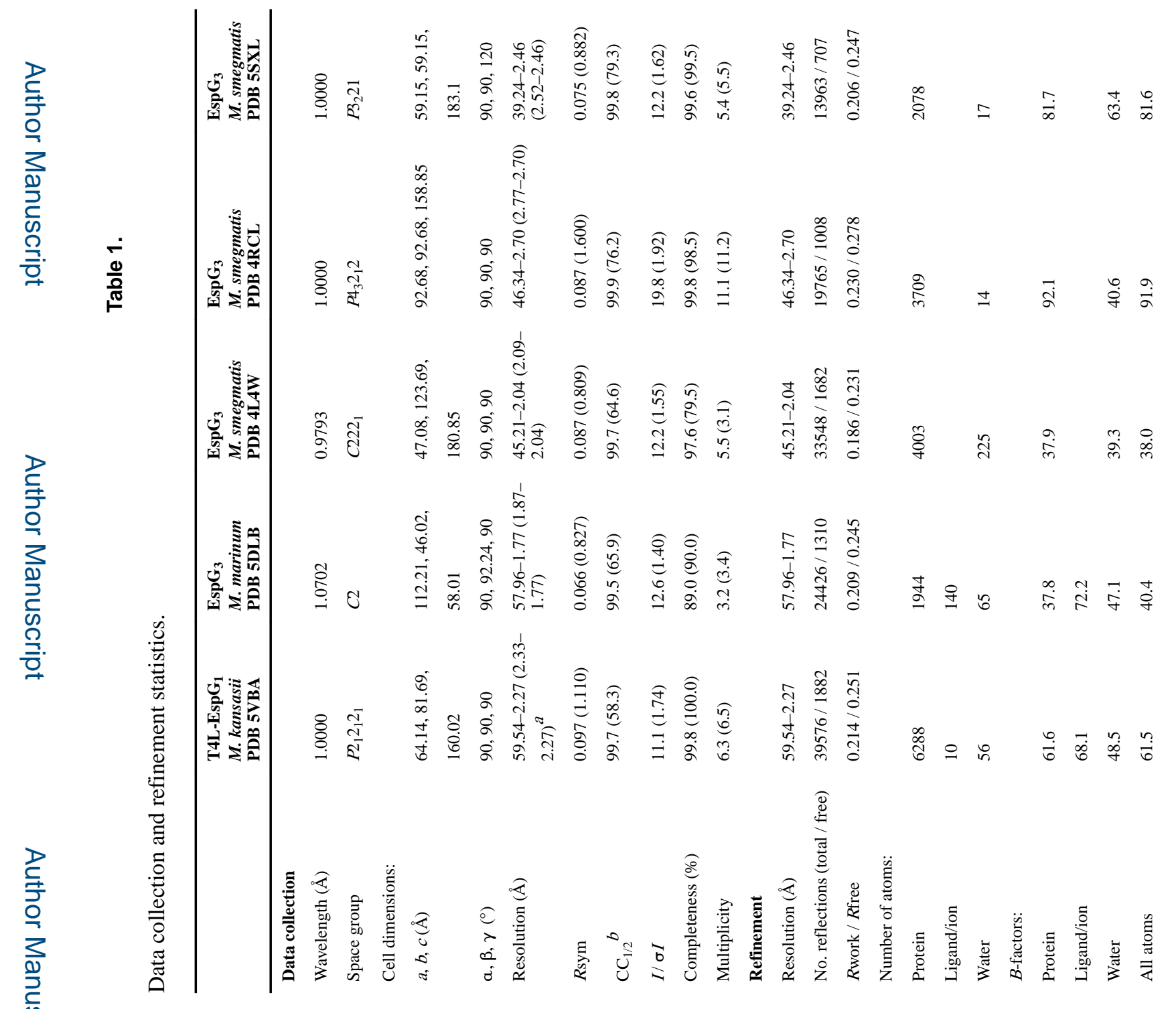

J Mol Biol. Author manuscript; available in PMC 2020 January 18. 


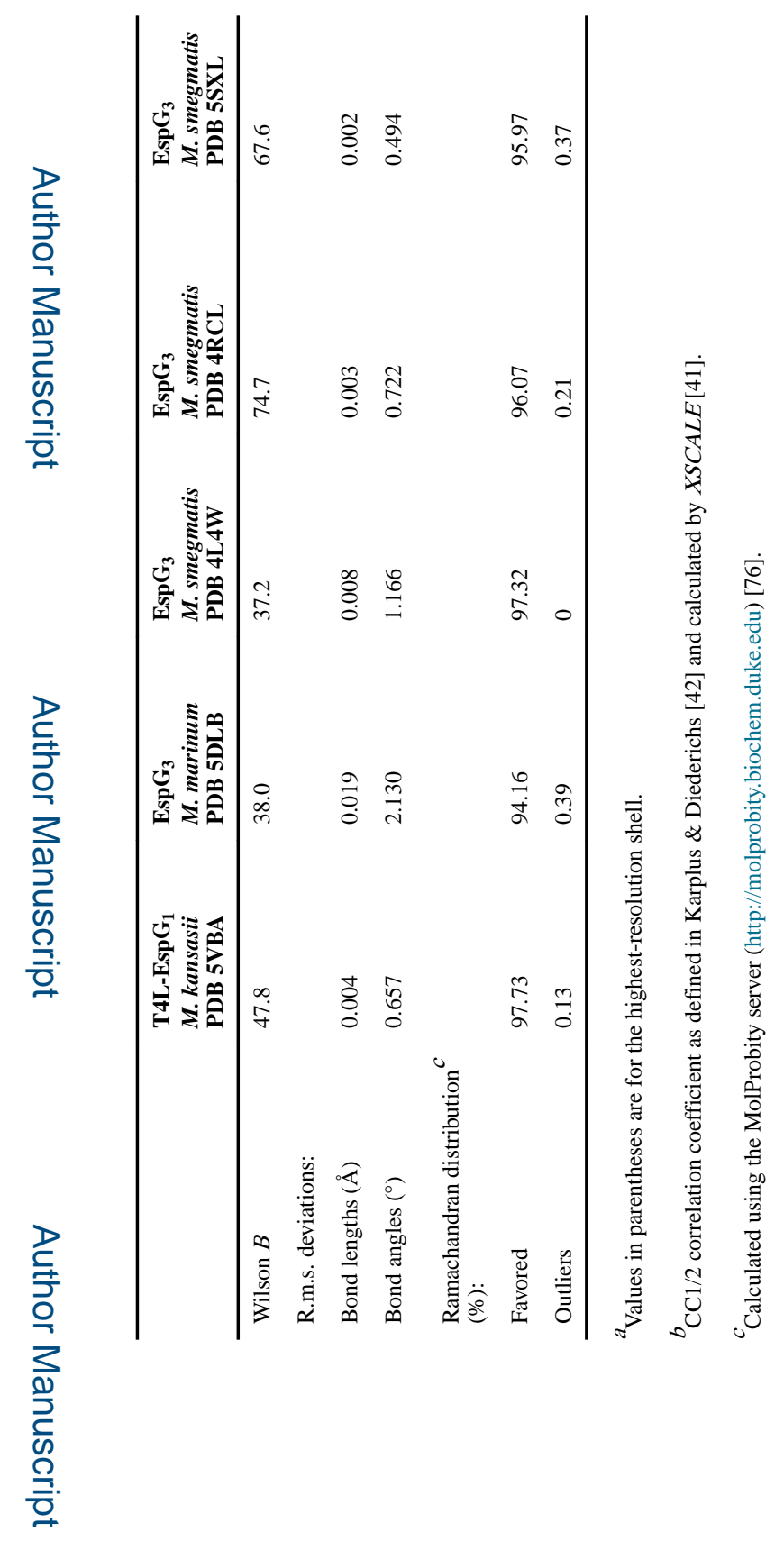

로을

J Mol Biol. Author manuscript; available in PMC 2020 January 18. 
Table 2.

Overview of EspG crystal structures.

\begin{tabular}{|c|c|c|c|c|c|}
\hline Chaperone & PDB ID & Structure & Oligomerization & Species & Reference \\
\hline \multirow[t]{4}{*}{ EspG $_{1}$} & $5 \mathrm{VBA}$ & & $\begin{array}{l}\text { Monomer } \\
\text { (dimerisation of } \\
\text { T4L) }\end{array}$ & M. kansasii & This work \\
\hline & $4 \mathrm{~L} 4 \mathrm{~W}$ & & $\begin{array}{l}\text { Wing-shaped } \\
\text { dimer }\end{array}$ & M. smegmatis & This work \\
\hline & \multicolumn{2}{|l|}{ 4RCL } & $\beta 8$-mediated & \multicolumn{2}{|l|}{ M. smegmatis } \\
\hline & $5 \mathrm{SXL}$ & & Monomer & \multirow[t]{2}{*}{ M. smegmatis } & \\
\hline \multicolumn{5}{|l|}{ EspG $_{3}$} & \\
\hline & $4 \mathrm{~W} 4 \mathrm{~J}$ & & $\begin{array}{l}\text { Wing-shaped } \\
\text { dimer }\end{array}$ & M. smegmatis & {$[27]$} \\
\hline & \multicolumn{2}{|l|}{$4 \mathrm{~W} 4 \mathrm{I}$} & Monomer & M. tuberculosis & {$[27]$} \\
\hline & \multicolumn{2}{|l|}{$5 \mathrm{DLB}$} & Monomer & M. marinum & This work \\
\hline & $4 \mathrm{KXR}$ & & $\begin{array}{l}\text { Complex with } \\
\text { PE25-PPE41 }\end{array}$ & M. tuberculosis & {$[26]$} \\
\hline $\operatorname{EspG}_{5}$ & $4 \mathrm{~W} 4 \mathrm{~L}$ & & $\begin{array}{l}\text { Complex with } \\
\text { PE25-PPE41 }\end{array}$ & M. tuberculosis & [27] \\
\hline & $5 \mathrm{XFS}$ & & $\begin{array}{l}\text { Complex with } \\
\text { PE8-PPE15 }\end{array}$ & M. tuberculosis & [34] \\
\hline
\end{tabular}


Table 3.

\section{Collected SAXS data}

\begin{tabular}{|c|c|c|c|c|c|c|c|c|c|}
\hline \multicolumn{10}{|c|}{ Data collection parameters } \\
\hline \multicolumn{2}{|l|}{ Instrument } & \multicolumn{8}{|c|}{ P12 at EMBL/DESY, storage ring PETRA III, Germany } \\
\hline \multicolumn{2}{|c|}{ Beam geometry $\left(\mathrm{mm}^{2}\right)$} & \multicolumn{8}{|l|}{$0.2 \times 0.12$} \\
\hline \multicolumn{2}{|c|}{ Wavelength (Å) } & \multicolumn{8}{|l|}{1.24} \\
\hline \multicolumn{2}{|c|}{$q$-range $\left(\AA^{-1}\right)$} & \multicolumn{8}{|l|}{$0.0023-0.47$} \\
\hline \multicolumn{2}{|c|}{ Exposure time (ms) } & \multicolumn{8}{|l|}{$20 \times 50$} \\
\hline \multicolumn{2}{|c|}{ Temperature (K) } & \multicolumn{8}{|l|}{283} \\
\hline \multicolumn{2}{|l|}{ Instrument } & \multicolumn{8}{|c|}{ B21 at Diamond Light Source, United kingdom } \\
\hline \multicolumn{2}{|c|}{ Beam geometry $\left(\mathrm{mm}^{2}\right)$} & \multicolumn{8}{|l|}{$1.0 \times 5.0$} \\
\hline \multicolumn{2}{|c|}{ Wavelength $(\AA)$} & \multicolumn{8}{|l|}{1.0} \\
\hline \multicolumn{2}{|l|}{$q$-range $\left(\AA^{-1}\right)$} & \multicolumn{8}{|l|}{$0.0038-0.42$} \\
\hline \multicolumn{2}{|c|}{ Exposure time (ms) } & \multicolumn{8}{|l|}{$60 \times 100$} \\
\hline \multicolumn{2}{|c|}{ Temperature (K) } & \multicolumn{8}{|l|}{283} \\
\hline Structural pa & ameters & & & & & & & & \\
\hline Sample & $\begin{array}{c}\text { Conc. } \\
\left(\mathrm{mg} \mathrm{ml}^{-1}\right)\end{array}$ & $\underset{(\mathrm{nm})}{R g, \text { Guinier }}$ & $\begin{array}{l}R g, P r \\
(\mathrm{~nm})\end{array}$ & $\begin{array}{c}D \max \\
(\mathrm{nm})\end{array}$ & $\begin{array}{c}\text { MMtheor } \\
(\mathrm{kDa})\end{array}$ & $\underset{(\mathrm{kDa})}{M M S A X S}$ & $\begin{array}{c}\text { MMPOROD } \\
\quad(\mathrm{kDa})\end{array}$ & $\begin{array}{c}M M D A M \\
\quad(\mathrm{kDa})\end{array}$ & $\begin{array}{c}\text { Ab initio } \\
\text { resolution, } \\
(\AA)\end{array}$ \\
\hline & 1.0 & 2.7 & 2.9 & 9.7 & 29.8 & 25.0 & 43.0 & & \\
\hline $\mathrm{FsnG}_{1}$ & 2.0 & 3.2 & 3.1 & 11.0 & 29.8 & 32.0 & 55.0 & 150 & 28 \\
\hline $\mathrm{Espu}_{1 \mathrm{mma}}$ & 4.2 & 3.4 & 3.5 & 11.0 & 29.8 & 37.0 & 65.0 & 45.0 & $42 \pm 3$ \\
\hline & 6.0 & 3.5 & 3.6 & 12.0 & 29.8 & 40.0 & 72.0 & & \\
\hline & 1.1 & 2.5 & 2.6 & 9.0 & 31.6 & 23.0 & 41.0 & & \\
\hline $\mathrm{FsnG}_{2}$ & 2.0 & 2.8 & 3.0 & 10.0 & 31.6 & 30.0 & 47.0 & 410 & $34+3$ \\
\hline La & 4.0 & 3.2 & 3.1 & 10.0 & 31.6 & 32.0 & 56.0 & 41.0 & $34 \pm 3$ \\
\hline & 6.1 & 3.5 & 3.5 & 12.0 & 31.6 & 39.0 & 68.0 & & \\
\hline & 1.1 & 2.3 & 2.5 & 8.0 & 32.0 & 20.0 & 39.0 & 34.0 & \\
\hline$F_{s n} C$ & 2.1 & 2.3 & 2.4 & 8.0 & 32.0 & 22.0 & 35.0 & 35.0 & $22+2$ \\
\hline $\mathrm{Lspu}_{3 \mathrm{mma}}$ & 4.0 & 2.3 & 2.4 & 8.0 & 32.0 & 21.0 & 40.0 & 38.0 & $23 \pm 2$ \\
\hline & 6.0 & 2.3 & 2.3 & 8.0 & 32.0 & 22.0 & 44.0 & 36.0 & \\
\hline & 0.8 & 2.5 & 2.6 & 8.6 & 31.6 & 20.5 & 39.0 & 48.0 & \\
\hline $\mathrm{EspG}_{2}$ & 1.8 & 2.5 & 2.5 & 8.8 & 31.6 & 21.4 & 32.0 & 41.0 & $36+3$ \\
\hline & 3.9 & 2.6 & 2.6 & 9.3 & 31.6 & 22.1 & 39.0 & 44.0 & \\
\hline & 6.2 & 2.8 & 2.7 & 9.7 & 31.6 & 24.0 & 39.0 & 47.0 & \\
\hline & 0.9 & 2.5 & 2.5 & 9.2 & 31.6 & 22.5 & 38.0 & & \\
\hline $\begin{array}{c}\text { EspG3msm } \\
\text { Se-Met }\end{array}$ & 2.1 & 2.5 & 2.6 & 9.2 & 31.6 & 22.5 & 38.0 & 43.0 & $39 \pm 3$ \\
\hline & 3.8 & 2.6 & 2.6 & 9.2 & 31.6 & 24.3 & 40.0 & & \\
\hline & 0.9 & 2.3 & 2.5 & 8.0 & 32.4 & 23.0 & 41.0 & & \\
\hline $\mathrm{FsnG}_{-}$ & 1.7 & 2.4 & 2.4 & 8.0 & 32.4 & 22.0 & 42.0 & 470 & $25+2$ \\
\hline Lspov 5 mtu & 4.1 & 2.4 & 2.5 & 8.0 & 32.4 & 21.0 & 43.0 & 4.0 & $2 J \pm 2$ \\
\hline & 6.7 & 2.4 & 2.4 & 8.0 & 32.4 & 22.0 & 41.0 & & \\
\hline
\end{tabular}




\begin{tabular}{|c|c|c|c|c|c|c|c|c|c|}
\hline \multicolumn{10}{|c|}{ Data collection parameters } \\
\hline $\begin{array}{c}\text { EspG }_{5 \mathrm{mtu}^{-}} \\
\text {PE25-- } \\
\text { PPE41 }\end{array}$ & 0.5 & 4.0 & 4.0 & 13.0 & 65.0 & 76.0 & 46.0 & 76.0 & $37 \pm 3$ \\
\hline $\begin{array}{l}\text { EspG3 }{ }_{\mathrm{msm}}- \\
\text { PE5-PPE4 }\end{array}$ & 1.2 & 4.0 & 4.2 & 14.2 & 95.0 & 83.0 & 52.0 & 83.0 & $38 \pm 3$ \\
\hline
\end{tabular}


Table 4.

Oligomer analysis using the crystallographic monomer and dimer structures of EspG proteins.

\begin{tabular}{|c|c|c|c|c|c|}
\hline Sample & $\begin{array}{l}\text { Template } \\
\text { (PDB ID) }\end{array}$ & $\begin{array}{l}\text { Concentration } \\
\quad\left(\mathrm{mg} \mathrm{ml}^{-1}\right)\end{array}$ & $\begin{array}{l}\text { Monomeric } \\
\text { Fraction }\end{array}$ & $\begin{array}{l}\text { Dimeric } \\
\text { fraction }\end{array}$ & $\begin{array}{l}\text { Goodness-of- } \\
\text { fit, } \chi^{2}\end{array}$ \\
\hline \multirow{8}{*}{$\mathrm{EspG}_{1 \mathrm{mma}}$} & \multirow{4}{*}{$\begin{array}{c}\beta 8 \text {-mediated } \\
\text { dimer } \\
(4 \mathrm{RCL})\end{array}$} & 1.0 & 0.94 & 0.06 & 0.80 \\
\hline & & 2.0 & 0.74 & 0.26 & 0.93 \\
\hline & & 4.2 & 0.58 & 0.42 & 1.44 \\
\hline & & 6.0 & 0.50 & 0.50 & 1.90 \\
\hline & \multirow{4}{*}{$\begin{array}{l}\text { Wing-shaped } \\
\text { dimer } \\
(4 \mathrm{~L} 4 \mathrm{~W})\end{array}$} & 1.0 & 0.93 & 0.07 & 0.79 \\
\hline & & 2.0 & 0.72 & 0.28 & 0.86 \\
\hline & & 4.2 & 0.54 & 0.46 & 1.01 \\
\hline & & 6.0 & 0.43 & 0.57 & 1.27 \\
\hline \multirow{4}{*}{$\mathrm{EspG}_{3 \mathrm{mtu}}$} & \multirow{4}{*}{$\begin{array}{l}\text { Wing-shaped } \\
\text { dimer } \\
(4 \mathrm{~L} 4 \mathrm{~W})\end{array}$} & 1.1 & 0.537 & 0.462 & 0.89 \\
\hline & & 2.0 & 0.364 & 0.636 & 0.90 \\
\hline & & 4.0 & 0.113 & 0.887 & 0.95 \\
\hline & & 6.1 & 0.0 & 0.999 & 0.89 \\
\hline \multirow{4}{*}{$\mathrm{EspG}_{3 \mathrm{mma}}$} & \multirow{4}{*}{$\begin{array}{c}\text { Wing-shaped } \\
\text { dimer } \\
(4 \mathrm{~L} 4 \mathrm{~W})\end{array}$} & 1.1 & 0.531 & 0.468 & 0.82 \\
\hline & & 2.1 & 0.195 & 0.805 & 0.88 \\
\hline & & 4.0 & 0.000 & 1.000 & 1.05 \\
\hline & & 6.0 & 0.00 & 1.000 & 1.69 \\
\hline \multirow{4}{*}{$\begin{array}{l}\mathrm{EspG}_{3 \mathrm{msm}} \\
\text { (Native) }\end{array}$} & \multirow{4}{*}{$\begin{array}{l}\text { Wing-shaped } \\
\text { dimer } \\
(4 \mathrm{~L} 4 \mathrm{~W})\end{array}$} & 0.78 & 0.589 & 0.410 & 0.90 \\
\hline & & 1.75 & 0.654 & 0.346 & 1.32 \\
\hline & & 3.94 & 0.575 & 0.425 & 1.35 \\
\hline & & 6.24 & 0.449 & 0.550 & 2.03 \\
\hline \multirow{3}{*}{$\begin{array}{l}\text { EspG }_{3 \mathrm{msm}} \\
\text { (SetMet) }\end{array}$} & \multirow{3}{*}{$\begin{array}{c}\text { Wing-shaped } \\
\text { dimer } \\
(4 \mathrm{~L} 4 \mathrm{~W})\end{array}$} & 0.90 & 0.70 & 0.30 & 0.92 \\
\hline & & 2.14 & 0.70 & 0.30 & 1.80 \\
\hline & & 3.79 & 0.59 & 0.41 & 2.50 \\
\hline
\end{tabular}

